\title{
Hydrothermal Carbonization of Argan Nut Shell: Functional Mesoporous Carbon with Excellent Performance in the Adsorption of Bisphenol A and Diuron
}

\author{
Mohamed Zbair ${ }^{1,2,3}$ (D) Michael Bottlinger ${ }^{2} \cdot$ Kaisu Ainassaari $^{3} \cdot$ Satu Ojala $^{3}$ - Oliver Stein ${ }^{2} \cdot$ Riitta L. Keiski $^{3}$. \\ Mohammed Bensitel $^{1} \cdot$ Rachid Brahmi ${ }^{1}$
}

Received: 3 July 2018 / Accepted: 17 December 2018 / Published online: 26 December 2018

(c) The Author(s) 2018

\begin{abstract}
Hydrochar derived from Argan nut shell (ANS) was synthesized and applied to remove bisphenol A (BPA) and diuron. The results indicated that the hydrochar prepared at $200{ }^{\circ} \mathrm{C}$ (HTC@ANS-200) possessed a higher specific surface area $\left(42 \mathrm{~m}^{2} / \mathrm{g}\right.$ ) than hydrochar (HTC@ANS-180) prepared at $180{ }^{\circ} \mathrm{C}\left(17 \mathrm{~m}^{2} / \mathrm{g}\right)$. The hydrochars exhibited spherical particles, which are rich in functional groups. The HTC@ANS-200 exhibited high adsorption efficiency, of about 92\% of the BPA removal and 95\% of diuron removal. The maximum Langmuir adsorption capacities of HTC@ANS-200 at room temperature were $1162.79 \mathrm{mg} /$ for Bisphenol A and $833.33 \mathrm{mg} / \mathrm{g}$ for diuron (higher than most reported adsorbents). The adsorption process was spontaneous $\left(-\Delta \mathrm{G}^{\circ}\right)$ and exothermic $\left(-\Delta \mathrm{H}^{\circ}\right)$. Excellent reusability was reclaimed after five cycles, the removal efficiency showed a weak decrease of $4 \%$ for BPA and $1 \%$ for diuron. The analysis of Fourier transforms infrared spectrometry demonstrated that the aromatic $\mathrm{C}=\mathrm{C}$ and $\mathrm{OH}$ played major roles in the adsorption mechanisms of $\mathrm{BPA}$ and diuron in this study. The high adsorption capacity was attributed to the beneficial porosity (The pore size of HTC@ANS-200 bigger than the size of BPA and diuron molecule) and surface functional groups. BPA and diuron adsorption occurred also via multiple adsorption mechanisms, including pore filling, $\pi-\pi$ interactions, and hydrogen bonding interactions on HTC@ ANS-200.
\end{abstract}

Keywords Hydrothermal carbonization $\cdot$ Hydrochar $\cdot$ Adsorption mechanism $\cdot$ BPA $\cdot$ Diuron $\cdot \pi-\pi$ interaction

\section{Statement of Novelty}

Electronic supplementary material The online version of this article (https://doi.org/10.1007/s12649-018-00554-0) contains supplementary material, which is available to authorized users.

Mohamed Zbair

zbair.mohamed@gmail.com

Rachid Brahmi

rbrahmi1997@gmail.com

1 Laboratory of Catalysis and Corrosion of Materials (LCCM), Department of Chemistry, Faculty of Sciences of El Jadida, University of Chouaïb Doukkali, BP. 20, 24000 El Jadida, Morocco

2 Laboratory of Hydrothermal Carbonization Process, Umwelt-Campus Birkenfeld, Trier University of Applied Sciences, Trier, Germany

3 Environmental and Chemical Engineering, Faculty of Technology, University of Oulu, P.O. Box 4300, 90014 Oulu, Finland
To our knowledge, this is the first paper introduces a new technique to produce hydrochar from argan nut shell and its studies as an adsorbent for the removal of bisphenol A and diuron. This study does not only open up a novel way to recycle argan nut shell but also presents a beneficial approach to synthesize low-cost materials for wastewater treatment.

\section{Introduction}

Hydrothermal carbonization (HTC) or wet pyrolysis, was first studied by Friedrich Bergius in 1911, when he presented peat to aqueous treatment at $600{ }^{\circ} \mathrm{C}$ and 200 bars [1]. The point was to get an elective probability for bio-sourced powers and hydrogen production, constraining the formation of $\mathrm{CO}_{2}$, however, the treatment was not effective. A few years after the fact, he utilized cellulose in aqueous treatment at 
milder conditions: temperature of $200-330{ }^{\circ} \mathrm{C}$ and pressure up to 200 bars and he got a material advanced in carbon [2]. Through the subject on the formation of fluid and dissolvable mixes from coal, Bergius' examinations energized different researchers. Berl and Schmidt attempted diverse sorts of biomass crude materials in hydrothermal carbonization at various temperatures between 150 and $350{ }^{\circ} \mathrm{C}$ [3]. Schumacher et al. contemplated the impact of the $\mathrm{pH}$ [3-5]. Further, Berl et al. got understanding of the elemental composition of HTC materials and Haenel in 1992 explored the coal structure in these materials $[4,6]$. Numerous specialists utilized HTC to get diverse item results, however, the primary carbon spheres using HTC of glucose were accounted for by Wang et al. in [5]. HTC as an aqueous transformation procedure can overcome an extensive number of the challenges identified with the ordinary waste transformation procedures like the natural treatment of disposed of biomass [7, 8]. Carbonization offers the benefits of littler footprint/ land area required, the productive transformation of waste biomass and more prominent diminishment in waste volume. As HTC is a thermochemical system, waste biomasses are not a basic operational issue as in fertilizing the soil and in anaerobic processing. Additionally, in perspective of the moisture requirement, waste biomass is more suitable for conversion through HTC than other fundamental dry thermal transformation frameworks.

The HTC procedure holds a critical bit of the oxygen substance and the majority of its surface usefulness rather than dry pyrolysis in which the measure of oxygen in the last materials is significantly decreased. In normal, when sugars are submitted to HTC, the carbon content increments from 25 to $30 \%$ and the oxygen content is decreased from 53 to $27-30 \%$, which is still high oxygen content [9]. Amid the HTC procedure, biomass antecedents are wealthy in aromatic rings and hydroxyl anions. Nonetheless, biomass forerunners have been converted into hydrophilic hydrochar materials and thermochemically more steady at direct states of temperature and pressure. Surface functional groups play a key role in the adsorption of toxic inorganic and organic contaminants from wastewater [10-13]. Researchers used HTC for the simultaneous carbonization and functionalization of precursors in the presence of certain chemical agents. $\mathrm{Xu}$ et al. functionalized the surface of activated carbon by hydrothermal treatment with respect to glucose [13] whereas Demir-Cakan et al. provided details regarding the preparation of microspheres rich in carboxylate by hydrothermal carbonization of glucose in view of acrylic acid [14]. Lignocellulosic waste biomass is a promising raw material for the production of carbonaceous materials with functional surface properties, because of its high initial content of oxygen [15].

The objective of this study was to (i) prepare hydrochar by HTC from Argan Nut Shell (ANS) at $180^{\circ} \mathrm{C}$ and $200^{\circ} \mathrm{C}$, (ii) examine the microstructure and chemical composition of the produced hydrochar by several techniques and (iii) evaluate the potential practical application of the developed materials in adsorption of bisphenol A (BPA) and diuron from contaminated waters. Diuron (herbicide) and Bisphenol A (raw material to produce pesticides, polycarbonate plastics, and epoxy resins) are harmful compounds that are frequently detected in ground and surface waters due to their worldwide use [16-20]. Due to this, there is an increasing interest to discover viable technique for their destruction in contaminated waters. Adsorption has been found to be superior to other techniques for wastewater treatment due to its low-cost, high efficiency and simple operation. In this work, the adsorption behavior of the developed materials was modelled using standard isotherm equations and the associated kinetics and thermodynamics were analyzed.

\section{Materials and Methods}

\section{Reagents}

The chemicals used in this study were of analytical reagent grade and used without purification. Sulphuric acid $\mathrm{H}_{2} \mathrm{SO}_{4}$ (purity $>99 \%$ ), Bisphenol A, and Diuron (purity 99\%) were purchased from Sigma-Aldrich.

\section{Hydrothermal Carbonization of Argan Nut Shell}

The hydrothermal carbonization of Argan Nut Shell (ANS) was performed in a high-pressure autoclave (Fig. 1). The capacity of the autoclave is $3 \mathrm{~L}$ with a maximum working pressure of 60 bars and the temperature range of $180-300{ }^{\circ} \mathrm{C}$. The desired mass of ANS was loaded into the reactor with deionizer water (ratio $=1: 5)$, the $\mathrm{pH}$ was adjusted with $\mathrm{H}_{2} \mathrm{SO}_{4}(50 \%)$ to obtain $\mathrm{pH}$ 3. Then, two samples were hydrothermally carbonized, the first one at $180^{\circ} \mathrm{C}$ and the second one at $200{ }^{\circ} \mathrm{C}$ for $6 \mathrm{~h}$. After cooling the system, the solid products were isolated by filtration under vacuum, and then dried at $80{ }^{\circ} \mathrm{C}$ for $12 \mathrm{~h}$. These solid products were denoted as HTC@ANS-180 and HTC@ANS-200.

\section{Characterization of Hydrohars}

The moisture content, volatile matter content, Ash, and fixed carbon content of ANS, HTC@ANS-180, and HTC@ ANS-200 were measured using a standard protocol (ASTM D 3172-3175 standards).

The higher heating values (HHV) for the ANS, HTC@ ANS-180, and HTC@ANS-200 were measured using a bomb calorimeter (IKA, C200). All samples ( $0.2 \mathrm{~g}$ each) were dried at $105^{\circ} \mathrm{C}$ for $12 \mathrm{~h}$ prior to analysis. 
Fig. 1 Preparation of HTC@ ANS-180 and HTC@ ANS-200 by hydrothermal carbonization

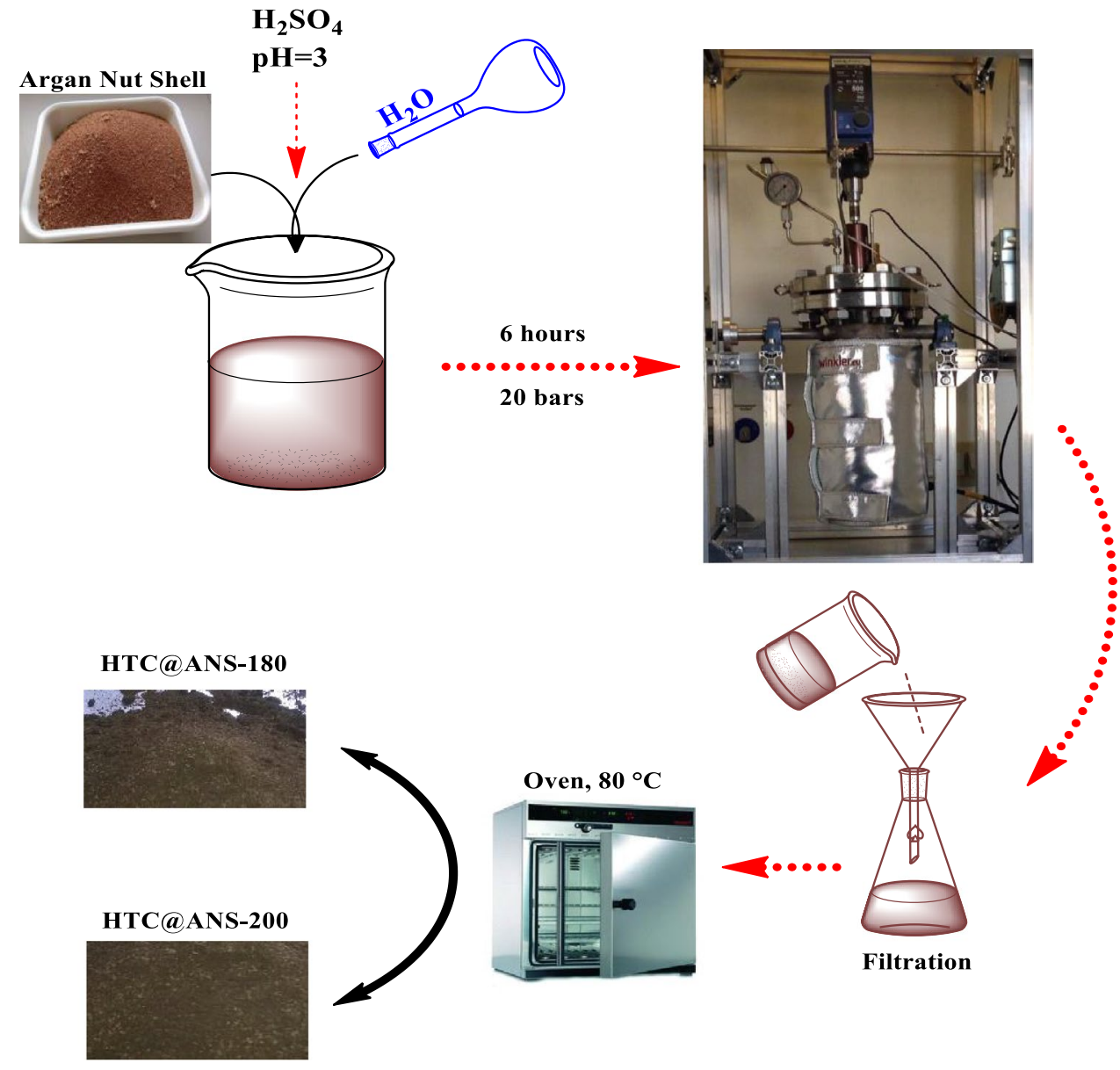

The yield percentage of HTC@ANS-180 and HTC@ ANS-200 was calculated by the following Eq. (1):

Hydrochar yield $\%=\frac{W_{H y}}{W_{R M}} \times 100$

where $W_{H y}$ is the weight of dry hydrochar and $W_{R M}$ is the weight of dry argan nut shell.

The X-ray diffraction (XRD) was measured for HTC@ ANS-180 and HTC@ANS-200 with an X-ray diffractometer (Bruker-eco D8 Advance diffractometer) using $\mathrm{Cu} \mathrm{K} \alpha$ radiation $(\lambda=1.5406 \AA)$. The crystallinity index $\left(C_{\mathrm{I}}\right)$ of HTC@ ANS-180 and HTC@ANS-200 was calculated using the Segal method (Eq. (2)) [21]. $\mathrm{I}_{200}$ represents both a crystalline and amorphous material, while $I_{a m}$ represents the amorphous material.

$C_{I}(\%)=\left(1-\frac{I_{a m}}{I_{200}}\right) \times 100$

Nitrogen physisorption analysis of HTC@ANS-180 and HTC@ANS-200 to determine the specific surface area and pore structure (BET-BJH) was carried out at $77 \mathrm{~K}$ in a
Micromeritics Tristar 3000. The morphological characteristics of argan nut shell (ANS), HTC@ANS-180, and HTC@ ANS-200 were analyzed using a Field Emission Scanning Electron Microscopy ZEISS ULTRA plus. The quantification of elemental concentrations in the raw material (ANS), HTC@ANS-180, and HTC@ANS-200 was done by using an S2 PICOFOX TXRF (Bruker AXS Microanalysis). Before analysis, around $100 \mathrm{mg}$ of sample was ground in a mortar and then suspended in a detergent solution of standard (Se) with concentration of $30 \mathrm{mg} / \mathrm{L}$. The point of zero charge (PZC) was determined using the $\mathrm{pH}$ drift method [22, 23]. The surface organic functional groups of ANS, HTC@ ANS-180, and HTC@ ANS-200 before and after adsorption of BPA and diuron were studied with a Fourier Transformed Infrared spectroscopy (FTIR-8409S, SHIMADZU). Before analysis, $\mathrm{KBr}$ was previously dried to avoid interferences due to the presence of water. The particle size of HTC@ ANS-180 and HTC@ANS-200 were measured by means of Fritsch Analysette 22 MicroTec plus. These measurements are based on laser diffraction in a convergent laser beam. For the measurements, the samples were dispersed in 
isopropanol and an ultrasonic dispersing system was used for $2 \mathrm{~min}$. The optical model used for the measurement was the Fraunhofer-scattering model.

\section{Adsorption Experiments}

The study was done utilizing batch experiments to evaluate the effect of temperature (293-333 K) and $\mathrm{pH}(2.0-12.0)$ on the adsorption of bisphenol A (BPA) and diuron. In each experiment, $200 \mathrm{~mL}$ of BPA $(60 \mathrm{mg} / \mathrm{L})$ and diuron $(40 \mathrm{mg} / \mathrm{L})$ solution were placed in a $250 \mathrm{~mL}$ Erlenmeyer flask and $0.01 \mathrm{~g}$ of HTC@ANS-200 was added to the solution. The flask was stirred at $200 \mathrm{rpm}$ in an isothermal incubator shaker (Heidolph Unimax 1010, Germany). At the end of the adsorption experiment, the HTC@ ANS-200 was separated from the solution by using $0.2 \mu \mathrm{m}$ Millipore filters (polyether sulfon membrane; VWR-USA). The residual BPA and diuron concentrations in the liquid-phase were analyzed by using a UV/Vis spectrophotometer (Beckman DU-640i spectrophotometer, USA) at the maximum absorbance wavelength $\left(\lambda_{\max }\right)$ of $274 \mathrm{~nm}$ for BPA and $248.4 \mathrm{~nm}$ for diuron. The kinetics of the adsorption was determined by analyzing the removal of BPA and diuron from the solution at different time intervals. The adsorption equilibrium experiments of HTC@ANS-200 were carried out at different temperatures $(293,313$, and $333 \mathrm{~K})$ by stirring $0.01 \mathrm{~g}$ of HTC@ANS-200 and 200 mL of different concentrations for each molecule, BPA $(10-60 \mathrm{mg} / \mathrm{L})$ and diuron $(10-40 \mathrm{mg} / \mathrm{L})$ for $3 \mathrm{~h}$. Concerning the calculation of the removal efficiency and adsorption capacity, please see the Supplementary information.

\section{Adsorption Theory}

Equations and formulas of equilibrium models, kinetic models, intra-particle diffusion model, and thermodynamics are presented in the Supplementary information.

\section{Results and Discussion}

\section{Characterization of Hydrochar Materials}

\section{Proximate Analyses, Higher Heating Value (HHV), and Yield of Hydrochars}

Proximate analysis results show that there was a significant decrease in the volatile matter, from 72.2 to $52.6 \%$ and an increase in the fixed carbon content from 12.1 to $39.2 \%$ (Table 1). The increase in the fixed carbon is related to the elimination of volatile matter occurring during the HTC process [24]. It is expected that argan nut shell degrades more at higher temperatures resulting in the removal of volatile matters in higher quantity [25]. This was likewise noted in the current study. Fixed carbon is the amount of carbon, which is not easily degraded and has a potential for ground burial for carbon credits [26]. Ash content reduces after HTC treatments (Table 1) showing, as previously well documented in the literature, that water-soluble minerals transfer to the liquid phase [27-29].

The HHV values of HTC@ANS-180 and HTC@ANS200 were increased compared to ANS, due to the increased amount of fixed carbon (Table 1). The increased fixed carbon at higher temperatures improved the heating value of the product from $17.295 \mathrm{~kJ} / \mathrm{g}$ (ANS) to $24.533 \mathrm{~kJ} / \mathrm{g}$ (HTC@ ANS-200). It can be presumed that the value of the carbon is relative to the heating value. In addition, higher temperatures during HTC process promote dehydration, decarboxylation, and condensation reactions of the carbonization process, resulting in the higher heating values [30].

The yield of hydrochar was decreased at $200{ }^{\circ} \mathrm{C}$ due to thermal degradation of the ANS. About $70 \%$ of mass was recovered at $180{ }^{\circ} \mathrm{C}$ and this amount was decreased to $64 \%$ at $200{ }^{\circ} \mathrm{C}$. Indeed, the decline in the solid yield was observed with an increase in temperature, which may be due to any of the following three reasons: (1) higher primary decomposition, (2) secondary decomposition of solid residue, and (3)

Table 1 Proximate analysis, higher heating values, and hydrochar yields

\begin{tabular}{|c|c|c|c|c|}
\hline & \multicolumn{4}{|c|}{ Proximate analysis $\%$} \\
\hline & Fixed carbon & Volatile matter & Moisture & Ash \\
\hline ANS & 12.1 & 72.2 & 5.3 & 10.4 \\
\hline HTC@ ANS-180 & 22.3 & 62.3 & 6.9 & 8.5 \\
\hline \multirow[t]{2}{*}{ HTC@ANS200 } & 39.2 & 52.6 & 4.9 & 3.3 \\
\hline & Unit & ANS & HTC@ANS-180 & HTC@ANS-200 \\
\hline Higher heating value (HHV) & $\mathrm{kJ} / \mathrm{g}$ & 17.295 & 20.066 & 24.533 \\
\hline Yield (\%) & - & - & 70 & 64 \\
\hline
\end{tabular}


higher solubilization of components in hydrolysis liquors $[31,32]$.

\section{X-ray Diffraction Analysis}

The X-ray diffraction patterns of the HTC@ANS-180 and HTC@ ANS-200 samples are illustrated in Fig. 2. Three narrow, sharp peaks at $2 \theta$ values of around $16^{\circ}, 22.5^{\circ}$ and $34.5^{\circ}$ were observed due to the presence of crystalline cellulose in the sample [24]. The cellulose exhibits characteristic assignments of 110, 200, and 004 planes, respectively [21, 33, 34]. The crystallinity index of HTC@ ANS-180 and HTC@ ANS-200 was computed by the Segal technique [21]. The crystallinity index of the HTC@ANS-180 was figured to be $53.88 \%$ and it increased in the case of HTC@ANS-200 to $71.66 \%$ (due to the higher removal of amorphous hemicelluloses) [33]. Similar phenomenon was observed for Sugarcane Bagasse and wood in previous studies [21,35].

\section{Fourier Transform Infrared Spectroscopy (FTIR)}

The functional groups on the surface of ANS,HTC@ANS180, and HTC@ANS-200 were analyzed using FTIR spectroscopy and the results are depicted in Fig. 3. A broadband in the spectrum of ANS focused at $3436 \mathrm{~cm}^{-1}$ is attributed to the hydrogen fortified $\mathrm{O}-\mathrm{H}$. The bands were seen at $2923 \mathrm{~cm}^{-1}$ and $2852 \mathrm{~cm}^{-1}$ are identified with aliphatic $\mathrm{C}-\mathrm{H}$ extending vibrations $[36,37]$. The peaks are seen in $1800-1500 \mathrm{~cm}^{-1}$ zone for the most part result from $\mathrm{C}=\mathrm{O}$ extending vibrations of keto-carbonyl gatherings $\left(1740 \mathrm{~cm}^{-1}\right)$ and $\mathrm{C}=\mathrm{C}$ extending vibrations of aromatic rings (1636 and $1510 \mathrm{~cm}^{-1}$ ) of lignin [38]. The peaks are found in the scope of $1500-1300 \mathrm{~cm}^{-1}$ result essentially from $\mathrm{O}-\mathrm{H}$ twisting vibrations and aliphatic $\mathrm{CH}_{3}$ and $\mathrm{CH}_{2}$ distortions in cellulose and lignin structures. The vibrations are seen between 1300 and $1000 \mathrm{~cm}^{-1}$ are ascribed to the $\mathrm{C}-\mathrm{O}$ extending of alcohol, carboxyl, and phenol [39]. The FTIR band situated at $571 \mathrm{~cm}^{-1}$ ascribes to the in-plane ring twisting [40]. Cellulose in ANS can be described by the most astounding force band focused at $1032 \mathrm{~cm}^{-1}$ coming about because of the $\mathrm{C}-\mathrm{O}$ extending vibrations of alcohols and phenols [41]. This trademark band of cellulose is diminished and seems just as a shoulder in the spectrum of HTC@ ANS-200 since the cellulosic parts of the material decay amid the HTC treatment. A lot of oxygenated functional gatherings is kept up at the surface of HTC@ANS-180 and HTC@ ANS-200 after the HTC.

The bands identified with the $\mathrm{O}-\mathrm{H}$ extending vibrations of hydroxyl and carboxyl gatherings and additionally the aliphatic $\mathrm{C}-\mathrm{H}$ extending vibrations show up in
Fig. 2 X-ray diffraction of HTC@ANS-180 and HTC@ ANS-200

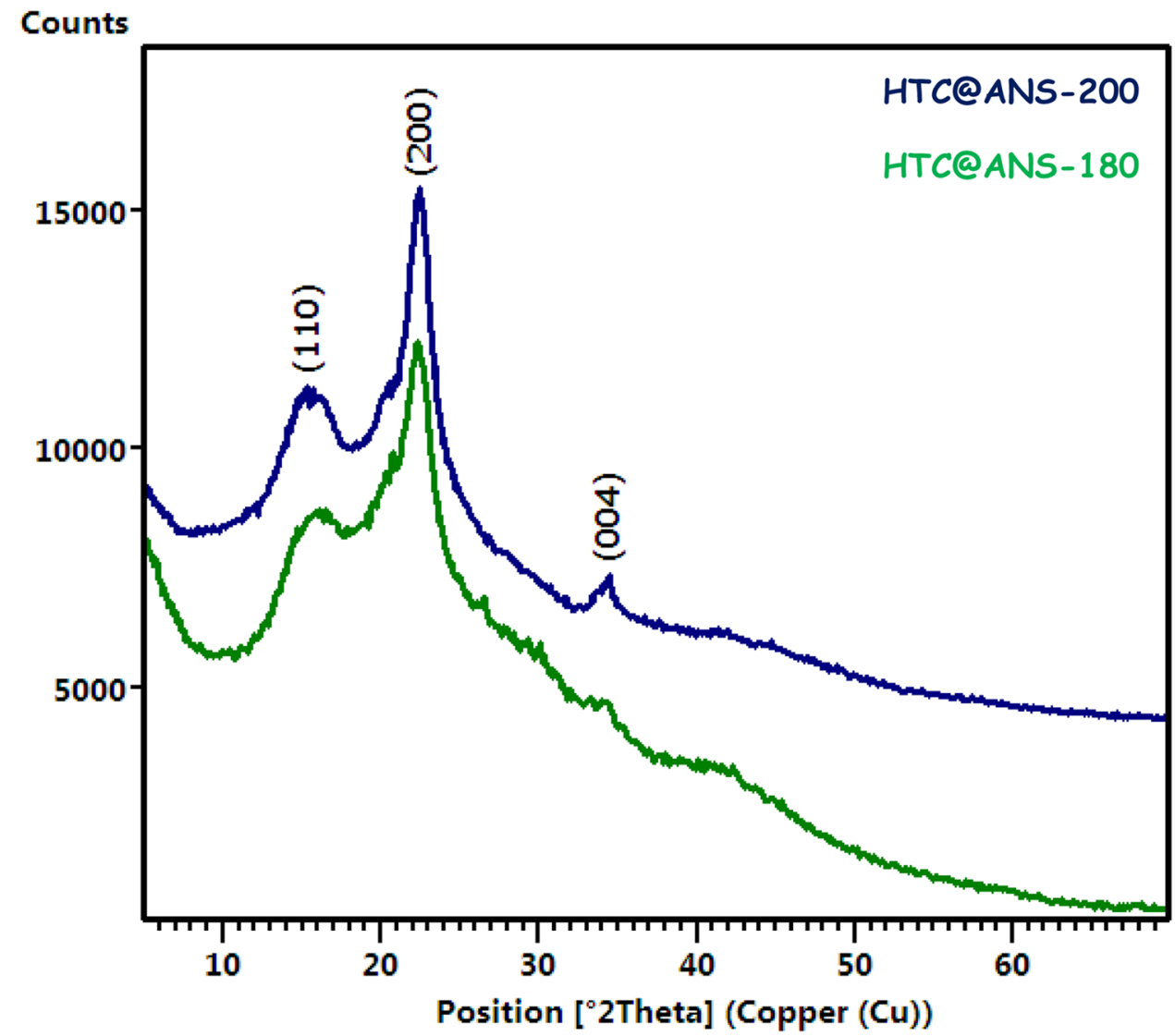


Fig. 3 Fourier transform infrared spectroscopy of: ANS, HTC@ANS-180, and HTC@ ANS-200

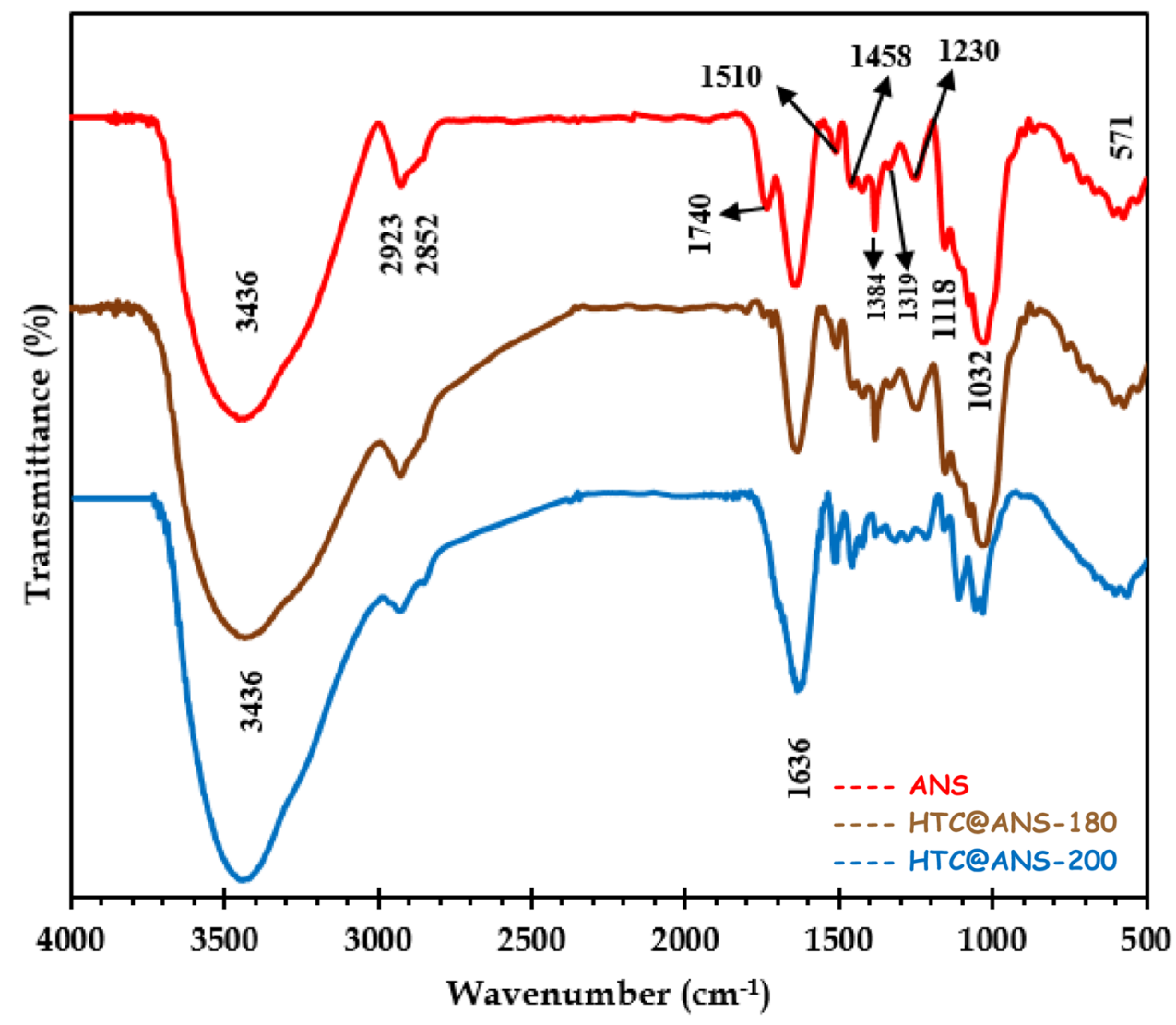

the $4000-2000 \mathrm{~cm}^{-1}$ region. The $\mathrm{C}=\mathrm{O}$ vibration vanished from the HTC treated examples. Conversely, $\mathrm{C}=\mathrm{C}$ peaks in the $1700-1000 \mathrm{~cm}^{-1}$ region were held with little moves and changes in intensities. Furthermore, the peaks identified with $\mathrm{O}-\mathrm{H}$ twisting and aliphatic $\mathrm{CH}_{3}$ and $\mathrm{CH}_{2}$ deformations were safeguarded. The intensity expanded in the $1500-1300 \mathrm{~cm}^{-1}$ region except for the peak situated at $1384 \mathrm{~cm}^{-1}$ for HTC@ANS-200, which may be due to the temperature impact.

The intensity of some peaks expanded in the $1300-1000 \mathrm{~cm}^{-1}$ region. These are ascribed to the $\mathrm{C}-\mathrm{O}$ extending vibrations of alcohol, phenol, and carboxylates. The oxygen-containing groups affirmed by the FTIR range acquired after the HTC procedure demonstrates a hydrophilic character of the material. The $\mathrm{C}-\mathrm{O}$ and $\mathrm{C}=\mathrm{C}$ extending vibration peaks $\left(1700-1000 \mathrm{~cm}^{-1}\right)$ were protected after the HTC procedure and the intensity of the $\mathrm{C}=\mathrm{C}$ peak expanded with an expanding level of aromatization on account of HTC@ANS-200. The peaks in the 1500-900 $\mathrm{cm}^{-1}$ part of HTC@ANS-200 are more extreme contrasted with ANS and HTC@ANS-180 with the main peak at $1032 \mathrm{~cm}^{-1}$ which is related with the $\mathrm{C}-\mathrm{O}$ extending, $\mathrm{C}-\mathrm{C}$ twisting and $\mathrm{CH}_{3}$ and $\mathrm{CH}_{2}$ distortions affirming the aromatization of the HTC@ANS-200 structure. The FTIR examination of our samples (ANS, HTC@ ANS-180, and HTC@ANS-200) affirms our speculation depicted in the introduction that the HTC-process monitors a critical part of the oxygen substance and a large portion of the surface functionalities exhibit in the crude material (ANS).

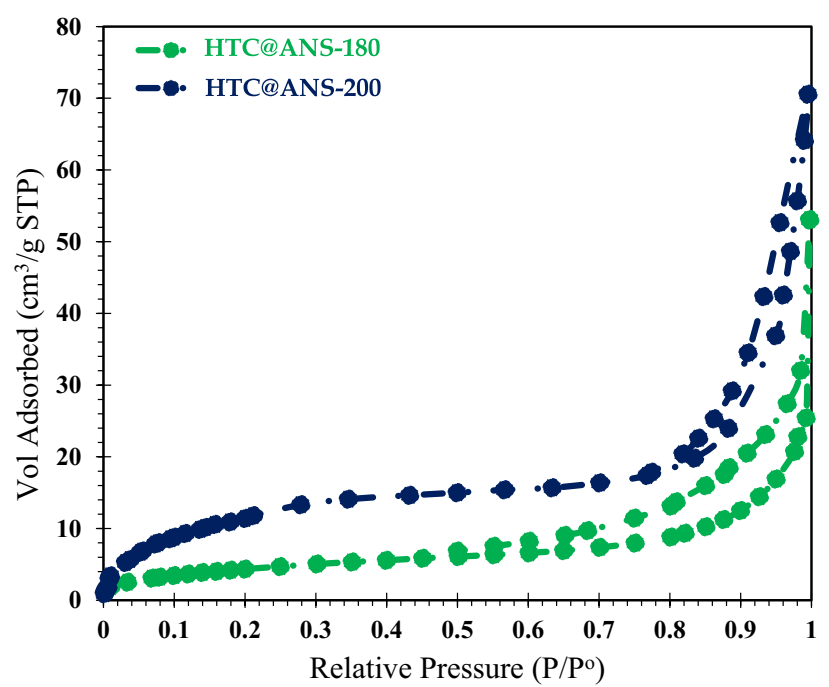

Fig. 4 Nitrogen adsorption-desorption isotherms at 77 K for HTC@ ANS-180 and HTC@ANS-200 
Table 2 Textural properties of the studied hydrochar materials

\begin{tabular}{clllll}
\hline $\begin{array}{l}\text { Hydrochar } \\
\text { materials }\end{array}$ & $\begin{array}{l}\text { BET sur- } \\
\text { face area } \\
\left(\mathrm{m}^{2} / \mathrm{g}\right)\end{array}$ & $\begin{array}{l}\text { External } \\
\text { surface } \\
\text { area } \\
\left(\mathrm{m}^{2} / \mathrm{g}\right)\end{array}$ & $\begin{array}{l}\text { Total pore } \\
\text { volume } \\
\left(\mathrm{cm}^{3} / \mathrm{g}\right)\end{array}$ & $\begin{array}{l}\text { Micropore } \\
\text { volume } \\
\left(\mathrm{cm}^{3} / \mathrm{g}\right)\end{array}$ & $\begin{array}{l}\text { Pore } \\
\text { size } \\
(\mathrm{nm})\end{array}$ \\
\hline $\begin{array}{c}\text { HTC@ } \\
\text { ANS- }\end{array}$ & 17 & 14 & 0.03 & 0.002 & 8 \\
$\begin{array}{c}180 \\
\text { HTC@ } \\
\text { ANS- }\end{array}$ & 42 & 19 & 0.08 & 0.001 & 2 \\
200 & & & & & \\
\hline
\end{tabular}

\section{Nitrogen Physisorption}

$\mathrm{N}_{2}$ adsorption-desorption isotherms of HTC@ ANS-180 and HTC@ANS-200, are shown in Fig. 4. The adsorption isotherms of HTC@ANS-180 and HTC@ANS-200, showed Type IV isotherms, showing the presence of large fractions of mesopores There is a clear H3-type hysteresis loop from P/P $=0.5$ to 0.99 for HTC@ ANS-180 and 0.76-0.99 for HTC@ANS-200. The Type H3 hysteresis loop, which does not exhibit any limiting adsorption at high P/P ${ }^{\circ}$ for HTC@ANS-180 and HTC@ANS-200, is typically observed with aggregates of plate-like particles giving rise to slit-shaped pores. HTC@ANS-200 exhibits a high BET surface area compared to HTC@ANS-180 (Table 2).

\section{Scanning Electron Microscopy (SEM)}

Scanning electron micrographs of the HTC@ ANS-180 and HTC@ ANS-200 spheres are exhibited in Fig. 5. As speculated in the introduction, both HTC@ANS-180 and HTC@ ANS-200 display interconnected spheres with generally uniform sizes, smooth outside surfaces, and standard round shapes. Sevilla and Fuertes [42], clarified that the development of the carbon material through the hydrothermal carbonization of glucose is credited to numerous responses (dehydration, polymerization, and aromatization). Fundamentally, each hydrochar frequently comprises of two sections: a hydrophobic center and a hydrophilic shell [43]. The HTC@ANS-180 and HTC@ANS-200 are obviously micrometer-sized spheres. However, the surface of HTC@ ANS-200 likewise shows some porosity, as noticeable in micrograph, which affirms the higher surface area $\left(42 \mathrm{~m}^{2} / \mathrm{g}\right)$ compared to HTC@ANS180 (17 m²/g).

\section{Total X-ray fluorescence spectroscopy (TXRF)}

In order to quantify the elements composition present in both prepared hydrochar HTC@ANS-180 and HTC@ANS-200,

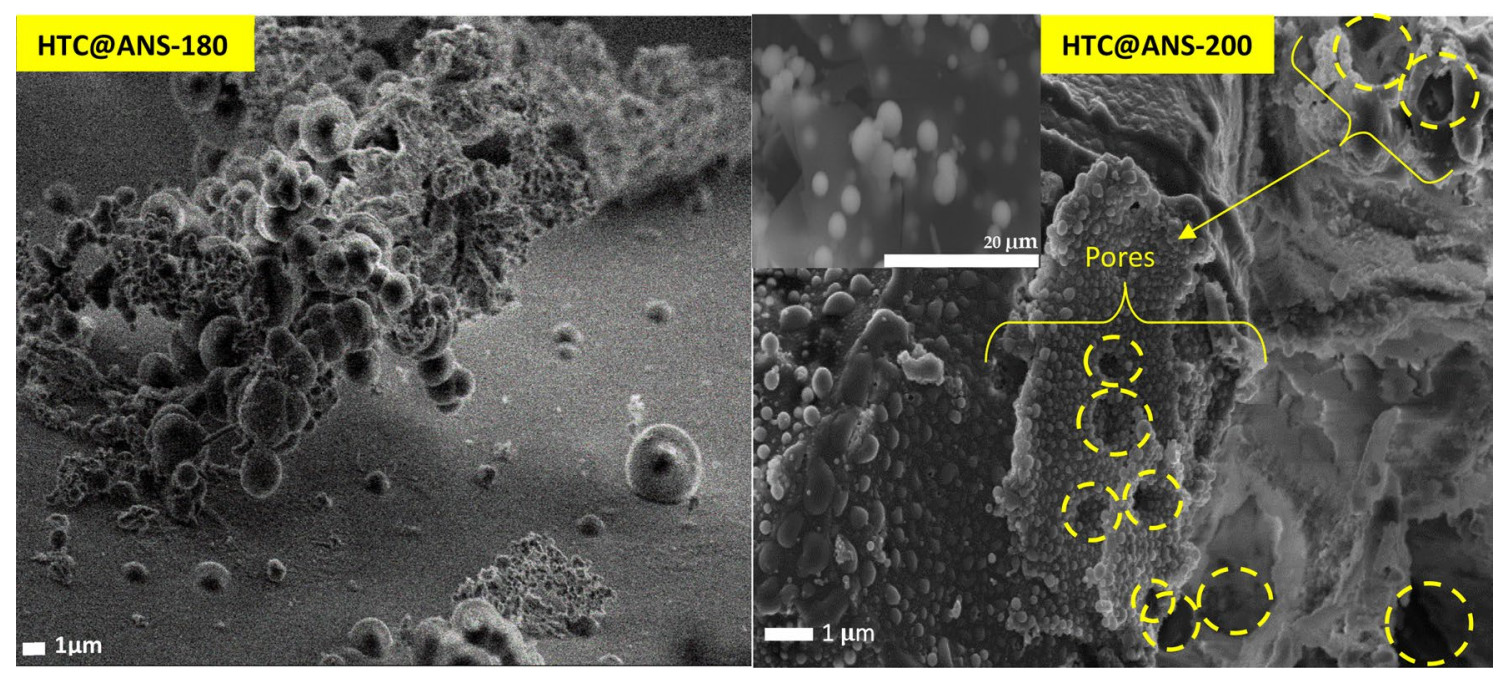

Fig. 5 Scanning electron microscopy (SEM) of the prepared hydrochar materials

Table 3 TXRF mean elemental concentrations (mg/Kg)

\begin{tabular}{llllllll}
\hline Element & $\mathrm{Al}(\mathrm{mg} / \mathrm{Kg})$ & $\mathrm{P}(\mathrm{mg} / \mathrm{Kg})$ & $\mathrm{S}(\mathrm{mg} / \mathrm{Kg})$ & $\mathrm{K}(\mathrm{mg} / \mathrm{Kg})$ & $\mathrm{Ca}(\mathrm{mg} / \mathrm{Kg})$ & $\mathrm{Fe}(\mathrm{mg} / \mathrm{Kg})$ & $\mathrm{Zn}(\mathrm{mg} / \mathrm{Kg})$ \\
\hline ANS & 124 & 560 & 287 & 1763 & 1518 & 186 & 7 \\
HTC@ ANS-180 & - & 201 & 989 & 632 & - & 130 & 6 \\
HTC@ ANS-200 & - & 164 & 1251 & 442 & - & 123 & 6 \\
\hline
\end{tabular}


TXRF analyses were carried out. Table 3 shows that the amount of a major part of the elements decreased after the HTC treatment. Sulphur in this case made an exception, since its amount was increased owing to sulphuric acid used in the $\mathrm{pH}$ adjustment of the mixture (distilled Water/Argan nut shell) before the HTC processing.

\section{Particle Size Distribution}

Figure 6 displays the cumulative curve of HTC@ANS-180 and HTC@ANS-200. The distribution for both the hydrochar materials are monomodal and the median size, $\mathrm{d} 50$, of HTC@ANS-180 is $41 \mu \mathrm{m}$ and for HTC@ANS-200 is $25 \mu \mathrm{m}$. We notice that the hydrochar (HTC@ANS-200) has a smaller particle size compared to the HTC@ ANS-180. At the same time, this result is in correlation with the specific
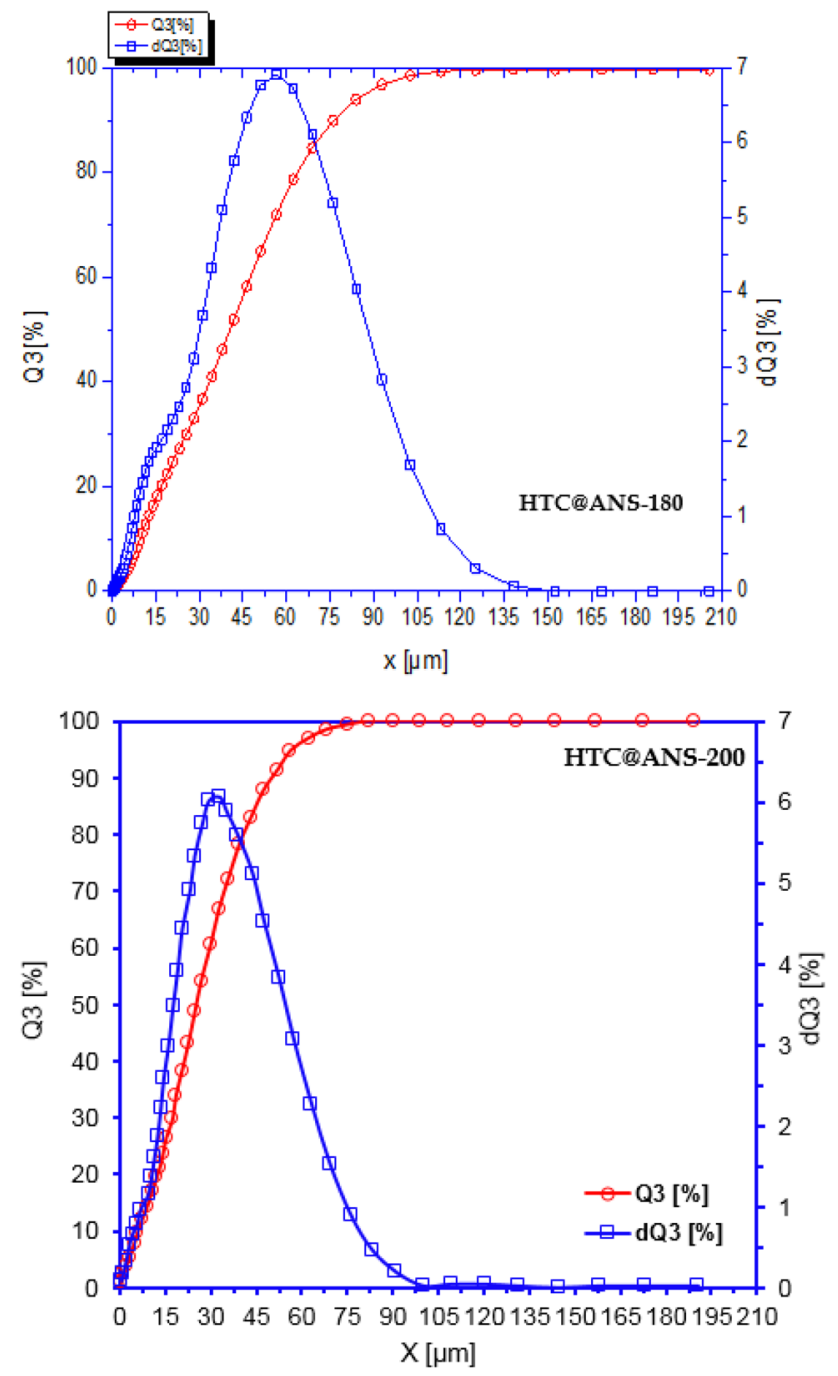

Fig. 6 The particle size distribution of HTC@ANS-180 and HTC@ ANS-200 surface area obtained in this work, the surface area increases with a decreasing particle size.

\section{BPA Adsorption Studies}

\section{BPA Removal by HTC@ANS-180 and HTC@ANS-200}

Preliminary adsorption tests were performed to find out the BPA and diuron removal efficiencies onto HTC@ANS-180 and HTC@ANS-200. From Fig.7 we conclude that HTC@ ANS-200 had a higher adsorption efficiency for BPA and diuron than HTC@ANS-180. This might be explained by the specific surface area of HTC@ANS-200 that is higher than that of HTC@ANS-180 (Table 2).

Another explanation for the high adsorption efficiency of HTC@ANS-200 can be attributed to the distribution of functional groups, as demonstrated by FTIR. Overall, it is interesting to note that HTC@ANS-200 with diverse functional groups and a greater specific surface area is more efficient for the adsorption of BPA and diuron. Henceforth, the further batch experiments were performed to evaluate the BPA and diuron adsorption characteristics of HTC@ ANS-200 only.

\section{Effect of $\mathrm{pH}$ of the Solution}

The effect of pH on adsorption behavior of HTC@ ANS-200 was studied by varying the $\mathrm{pH}$ of the solution between 2.0 and 12.0. The BPA removal was maximal at the acidic solution until the $\mathrm{pH}$ value 6.5 (Fig. 8). However, beyond the $\mathrm{pH}$ value 6.5 , the removal efficiency diminished with rising $\mathrm{pH}$. This behavior can be explained by the type of the surface charge of HTC@ANS-200 and the charge of BPA species at different initial pH values. HTC@ ANS-200 presents a net positive charge at solution $\mathrm{pH}$ value below their $\mathrm{pH}_{\mathrm{PZC}}$ (6.73) and a net negative charge at $\mathrm{pH}$ values above their $\mathrm{pH}_{\mathrm{PZC}}$ (Fig. 9). BPA will be found in its neutral form at $\mathrm{pH}$ values below 8 [44], and deprotonation is observed in significant extent at around $\mathrm{pH} 8$ [45]. Therefore, the decrease in the removal efficiency of HTC@ANS-200 observed at very basic $\mathrm{pH}$ values is due, in part, to the repulsive electrostatic interactions established between the negatively charged HTC@ANS-200 surface and the bisphenolate anion [44, 46, 47].

On the other hand, the removal percentage shown in Fig. 8. is stable between 6.7 and 12.0 corresponding to $\sim 95 \%$ removal of diuron and does not start to decrease after $\mathrm{pH}$ 6.7. This result can be explained as follows, diuron acts as cationic species at $\mathrm{pH}$ below 6.5 and a neutral molecule at $\mathrm{pH}$ above 6 [48]. At lower $\mathrm{pH}$, electrostatic repulsive interactions occur between the positive HTC@ANS-200 surface and the cationic diuron. At around $\mathrm{pH} 6.73$, both the diuron molecule and the HTC@ANS-200 surface is neutral; 
Fig. 7 Results of the preliminary adsorption tests of the removal of BPA and diuron by HTC@ANS-180 and HTC@ ANS-200 $\left(\mathrm{C}_{0}=60 \mathrm{mg} / \mathrm{L}\right.$; $\mathrm{m}=0.01 \mathrm{~g}$; agitation speed $=200 \mathrm{rpm}$ )

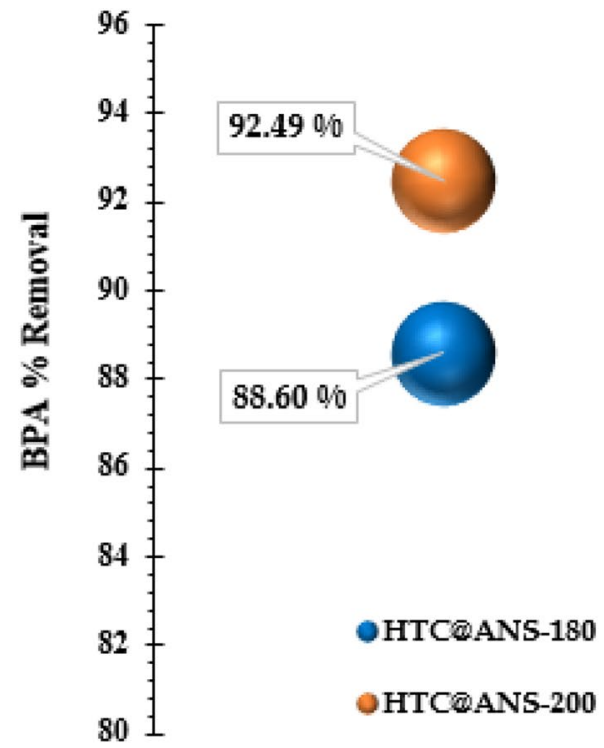

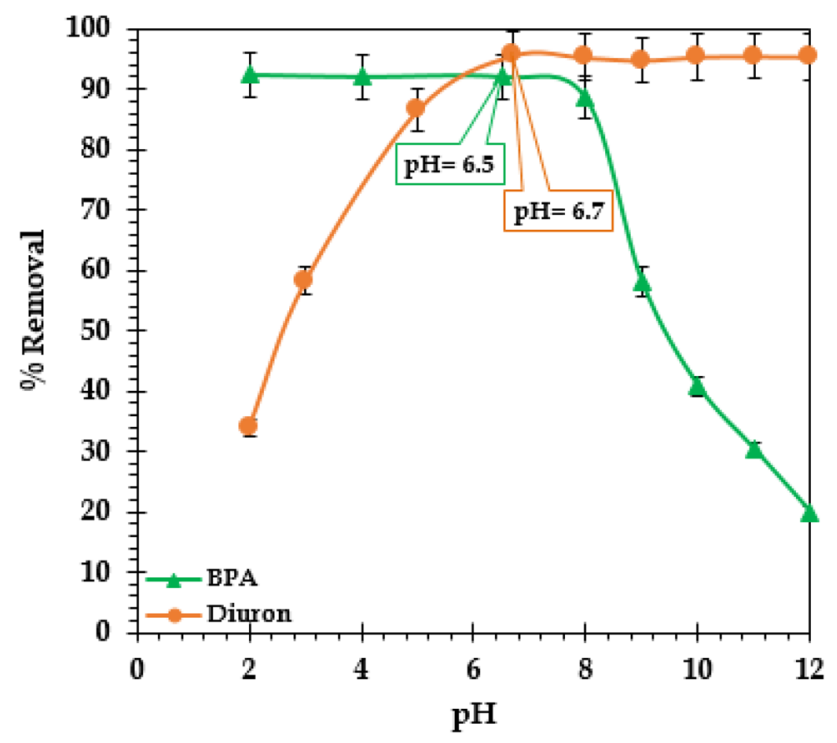

Fig. 8 Effect of initial $\mathrm{pH}$ on adsorption of BPA and diuron on HTC@ANS-200

hence, non-electrostatic interactions are predominated and the removal percentage stays at a higher level. At higher $\mathrm{pH}$, where the diuron molecule is neutral and the HTC@ANS200 surface is negatively charged, non-electrostatic interactions are predominant and the removal of diuron remains relatively constant.

\section{Effect of Temperature}

Figure 10 shows the BPA and diuron adsorption profiles of HTC@ANS-200 over the temperature range of 293-333 K.

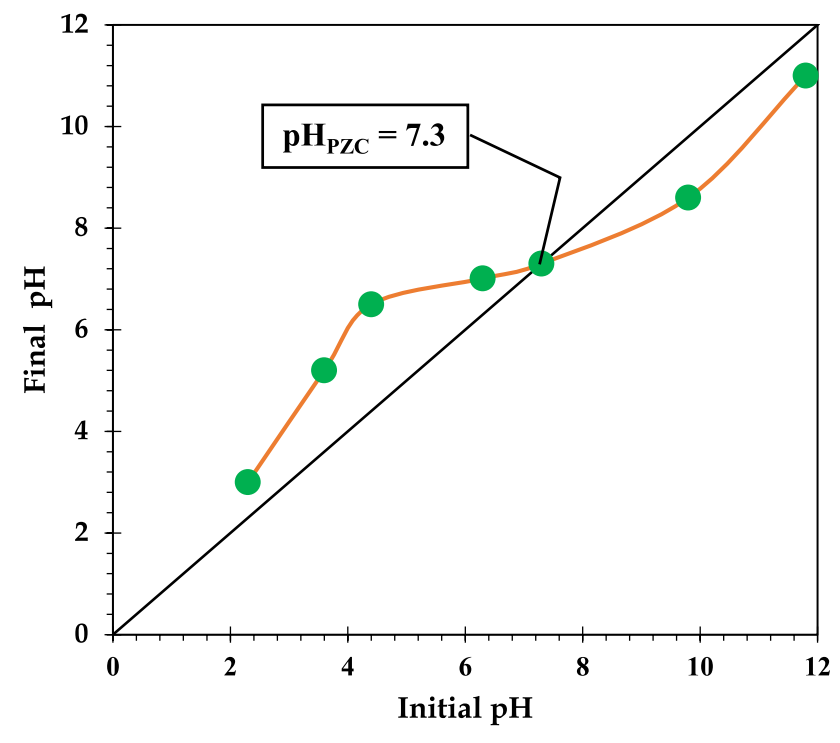

Fig. 9 pH $_{\text {PZC }}$ (point zero charge) of HTC@ ANS-200

The BPA and diuron adsorption capacity on HTC@ ANS200 decreased with rising temperature. In addition, diuron shows a fast adsorption rate during the first $30 \mathrm{~min}$ of the diuron/HTC@ANS-200 contact compared to BPA/HTC@ ANS-200, which needs $60 \mathrm{~min}$. The fast adsorption, which may be explained by an increased availability of diuron binding sites on HTC@ANS-200. The adsorption of BPA on HTC@ANS-200 decreased from 1094 to 664 mg/g and from 773 to $557 \mathrm{mg} / \mathrm{g}$ for diuron when increasing the temperature from 293 to $333 \mathrm{~K}$. This result indicates that a low temperature favours the adsorption of BPA and diuron on HTC@ANS-200. 

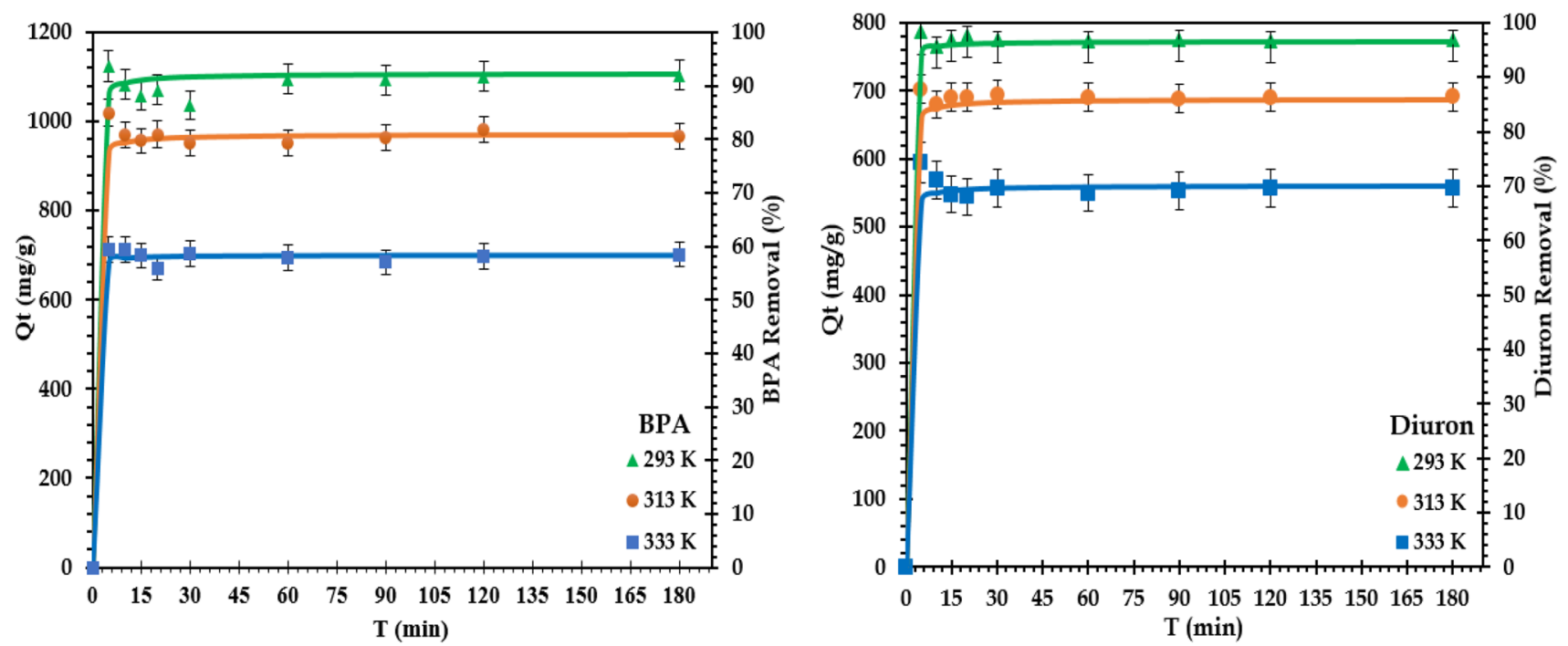

Fig. 10 Adsorption of BPA and diuron on HTC@ANS-200 at different temperatures. $\left(\mathrm{C}_{0}=60 \mathrm{mg} / \mathrm{L} ; \mathrm{m}=0.01 \mathrm{~g}\right.$; agitation speed =200 rpm $)$

\section{Adsorption Kinetics}

The kinetic data for the adsorption of BPA and diuron on HTC@ANS-200 were examined using the pseudo-first-order (PFO) and pseudo-second-order (PSO) equations [49]. The model constants were calculated using Eqs. (9) and (10) in Supplementary information.

The parameters obtained together with the $\mathrm{R}^{2}$ values are listed in Table 4. The high $\mathrm{R}^{2}$ values confirm that the BPA and diuron adsorption on HTC@ANS-200 data were well represented by the PSO kinetics over the entire adsorption period (Fig. 11). Also, the theoretical $Q_{e, c a l}$ values showed a good agreement with the experimental $Q_{e, \exp }$ values for both BPA and diuron, demonstrating further the applicability of this model. The increase in temperature accelerated the adsorption of BPA and diuron on HTC@ANS-200, which was certificated by the increase in the second-order rate constants $\left(\mathrm{K}_{2}\right)$. Liu et al. explained this by the decrease of solution viscosity at high temperature and thus promotes mass transfer and diffusion of the BPA and diuron molecules [50].

\section{The Intra-Particle Diffusion}

The intra-particle diffusion model proposed by Weber and Morris [51] was adopted to verify the mechanism controlling the BPA and diuron adsorption onto HTC@ANS-200, and can be defined as shown in Eq. (11) in Supplementary information.

The data-fitting curves are shown in Fig. 12. Note that the HTC@ANS-200 showed very similar adsorption kinetics for both the molecules. Furthermore, we notice the presence of several adsorption steps. Similar behavior of adsorption on mesoporous materials has been reported $[52,53]$. It can be observed that the adsorption of BPA and diuron on HTC@ ANS-200 displayed two different phases. The first phase is a fast adsorption step that mainly depends on the surface properties of HTC@ANS-200. This can be related to the macropore diffusion of BPA and diuron on HTC@ANS-200 [54]. However, the second phase represents mesopore diffusion and the final equilibrium adsorption stage of BPA and diuron on HTC@ANS-200 [54, 55].
Table 4 Parameters of PFO and PSO for the adsorption of BPA and diuron on HTC@ANS-200

\begin{tabular}{|c|c|c|c|c|c|c|c|}
\hline \multirow[t]{2}{*}{$\mathrm{T}(\mathrm{K})$} & \multirow[t]{2}{*}{$\mathrm{Q}_{\mathrm{e}, \exp }(\mathrm{mg} / \mathrm{g})$} & \multicolumn{3}{|c|}{ Pseudo-first-order } & \multicolumn{3}{|c|}{ Pseudo-second-order } \\
\hline & & $\mathrm{Q}_{\mathrm{e}, \mathrm{cal}}(\mathrm{mg} / \mathrm{g})$ & $\mathrm{K}_{1}$ (per min) & $\mathrm{R}^{2}$ & $\mathrm{Q}_{\mathrm{e}, \mathrm{cal}}(\mathrm{mg} / \mathrm{g})$ & $\mathrm{K}_{2}(\mathrm{~g} / \mathrm{mg} / \mathrm{min})$ & $\mathrm{R}^{2}$ \\
\hline \multicolumn{8}{|l|}{ BPA } \\
\hline 293 & 1094.71 & 5.24 & 0.010 & 0.115 & 1098.9 & 0.002 & 0.999 \\
\hline 313 & 950.43 & 5.24 & 0.028 & 0.480 & 970.8 & 0.018 & 0.999 \\
\hline 333 & 664.71 & 10.22 & 0.003 & 0.305 & 666.7 & 0.025 & 0.999 \\
\hline \multicolumn{8}{|c|}{ Diuron } \\
\hline 293 & 773.93 & 5.24 & 0.031 & 0.141 & 775.1 & 0.013 & 0.999 \\
\hline 313 & 694.38 & 5.17 & 0.031 & 0.143 & 694.4 & 0.148 & 0.999 \\
\hline 333 & 557.20 & 3.98 & 0.003 & 0.012 & 558.6 & 0.208 & 0.999 \\
\hline
\end{tabular}



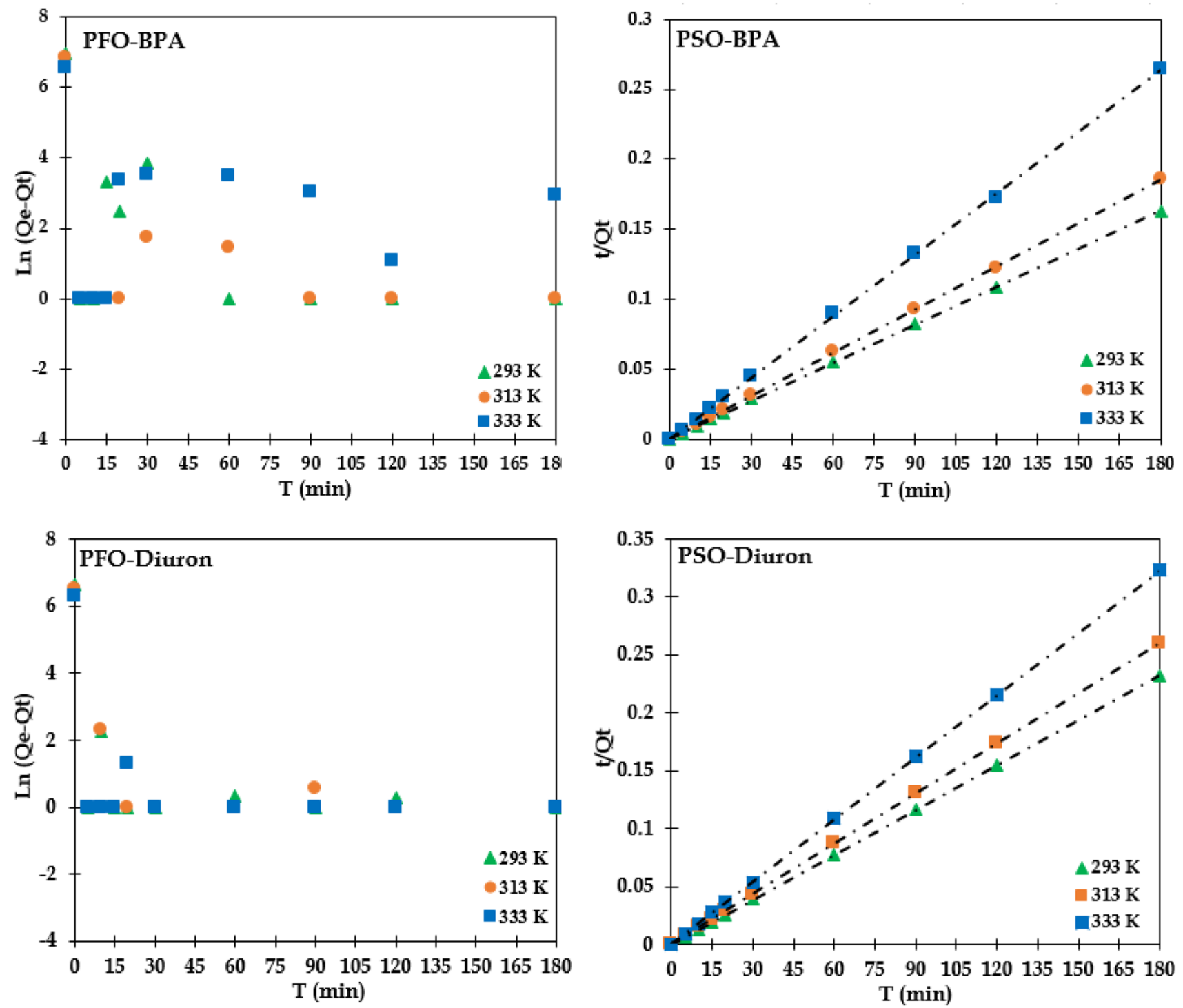

Fig. 11 Adsorption of BPA and diuron on HTC@ANS-200 fitted by the pseudo-first-order and pseudo-second-order models

\section{Adsorption Isotherms}

The adsorption isotherm study was done to describe the interactions between BPA and diuron on HTC@ANS-200. It is important for the interpretation of the surface properties, adsorption capacities of HTC@ANS-200 and to complete the adsorption isotherm study, the equilibrium data were fitted to the Langmuir model and the Freundlich model [56, 57]. The Langmuir and Freundlich parameters of BPA and diuron adsorption on HTC@ ANS-200 were calculated using Eqs. (6)-(8)in Supplementary information.

The isotherm parameters are listed in Table 5. On the basis of the comparison of the correlation coefficient $\left(\mathrm{R}^{2}\right)$ values of BPA and diuron adsorbed on HTC@ANS-200 (Fig. 13), the Langmuir model fitted the experimental data better than the Freundlich model for the both molecules BPA and diuron. This means that the adsorption of BPA and diuron on HTC@ ANS-200 represent monolayer adsorption. Even though the data were well described by the Langmuir model, the $\mathrm{R}^{2}$ values calculated for the Freundlich model are also significant $(0.85-0.97)$. The $\mathrm{R}_{\mathrm{L}}$ values of BPA and diuron are in the range of $0<\mathrm{R}_{\mathrm{L}}<1$, which indicates that the adsorption process on HTC@ ANS-200 was favourable. Similarly, to $R_{L}$, the $n$ values are significantly higher than 1 suggesting a favorable adsorption system and heterogeneity of the HTC@ ANS-200 adsorption sites. In addition, the two hydroxyl groups in the BPA molecule and the two nitrogen and oxygen atoms present in the diuron molecule may optionally cause the self-assembly of the BPA and diuron via 

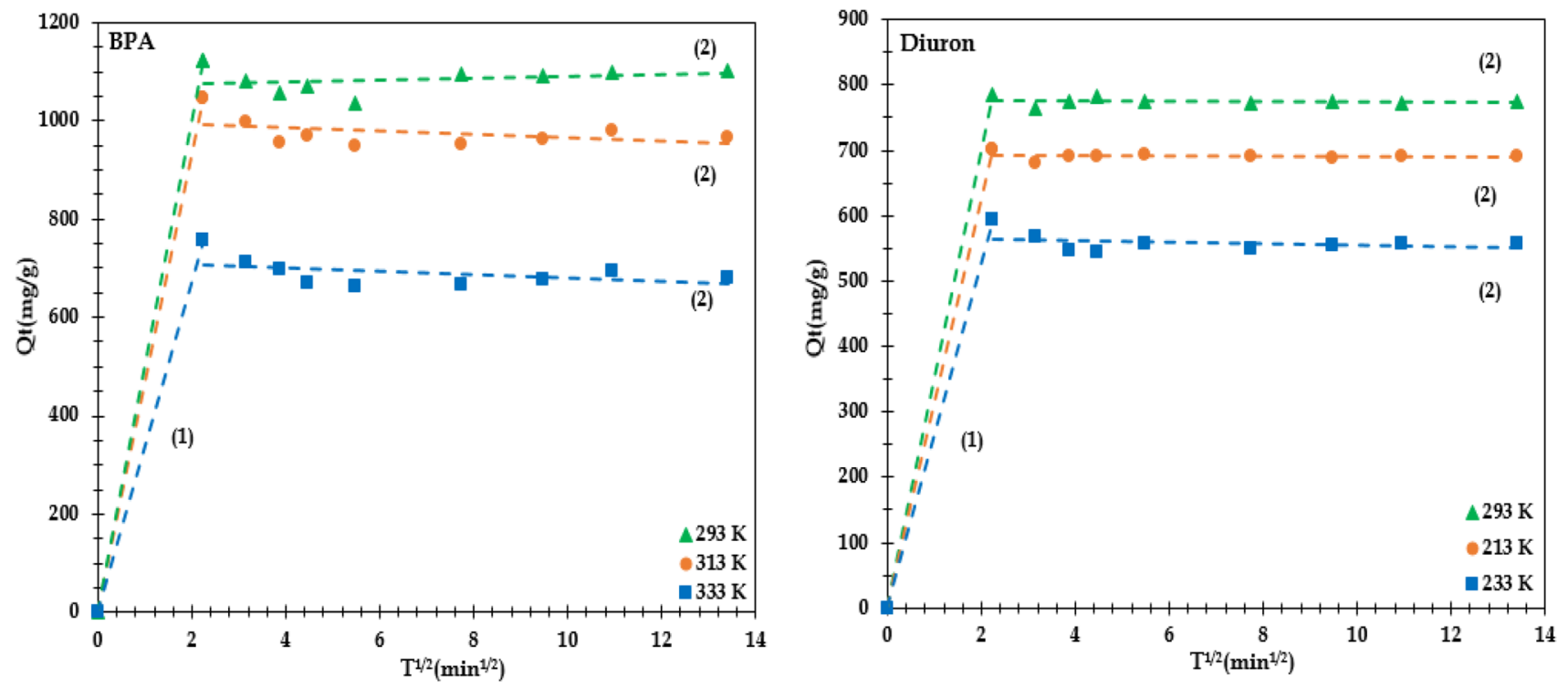

Fig. 12 Weber-Morris intra-particle diffusion model

Table 5 Parameters of Langmuir and Freundlich models of BPA and diuron on HTC@ANS-200

\begin{tabular}{|c|c|c|c|c|c|c|c|}
\hline \multirow[t]{2}{*}{$\mathrm{T}(\mathrm{K})$} & \multicolumn{4}{|l|}{ Langmuir } & \multicolumn{3}{|l|}{ Freundlich } \\
\hline & $\mathrm{Q}_{\max }(\mathrm{mg} / \mathrm{g})$ & $\mathrm{K}_{\mathrm{L}}(\mathrm{L} / \mathrm{mg})$ & $\mathrm{R}_{\mathrm{L}}$ & $\mathrm{R}^{2}$ & $\begin{array}{l}\mathrm{K}_{\mathrm{F}}((\mathrm{mg} / \mathrm{g}) / \\
\left.(\mathrm{mg} / \mathrm{L})^{\mathrm{n}}\right)\end{array}$ & $\mathrm{n}$ & $\mathrm{R}^{2}$ \\
\hline \multicolumn{8}{|l|}{ BPA } \\
\hline 293 & 1162.79 & 0.956 & 0.017 & 0.989 & 38.363 & 3.729 & 0.979 \\
\hline 313 & 909.09 & 0.499 & 0.032 & 0.984 & 159.988 & 1.841 & 0.963 \\
\hline 333 & 714.28 & 0.080 & 0.173 & 0.947 & 40.948 & 1.503 & 0.855 \\
\hline \multicolumn{8}{|c|}{ Diuron } \\
\hline 293 & 833.33 & 0.200 & 0.111 & 0.992 & 149.456 & 0.949 & 0.912 \\
\hline 313 & 769.23 & 0.134 & 0.157 & 0.947 & 85.884 & 1.028 & 0.865 \\
\hline 333 & 625.0 & 0.068 & 0.269 & 0.993 & 35.627 & 1.078 & 0.955 \\
\hline
\end{tabular}

hydrogen bonding, which leads to multilayer adsorption [58]. Since the adsorption mechanisms of BPA and diuron were better explained by the Langmuir model, the monolayer adsorption was concluded as the major mechanism and the multilayer adsorption is minor.

The maximum adsorption capacity of on HTC@ ANS-200 decreased from $1162.79 \mathrm{mg} / \mathrm{g}$ (293 K) to $714.28 \mathrm{mg} / \mathrm{g}(333 \mathrm{~K})$ and from $8.33 .33 \mathrm{mg} / \mathrm{g}(293 \mathrm{~K})$ to $625.0 \mathrm{mg} / \mathrm{g}(333 \mathrm{~K})$ for BPA and diuron, respectively. Obviously, higher adsorption capacities than the most earlier reported results obtained with other types of adsorbents (e.g., activated carbon, graphene, and graphite) were observed with HTC@ANS-200 (The comparison is shown in Table 6). Thus, the hydrothermal carbonization of Argan nut shell to hydrochar seems to be very interesting possibility to meet the wastewater discharge and water reuse requirements.

\section{Thermodynamic Parameters}

The thermodynamic parameters of BPA and diuron adsorption on HTC@ANS-200 (Fig. 14) were calculated using the Van't Hoff and Gibbs-Helmholtz equations [68]. (See Supplementary information, Eqs. 12, 13).

The $\Delta \mathrm{G}^{\circ}$ values of BPA and diuron exhibit a negative quantity, demonstrating that the adsorption process on HTC@ANS-200 occurred favorably and spontaneously with low adsorption-energy requirements at a given temperature. At the same time, the values of $\Delta \mathrm{G}^{\circ}$ became more negative with decreasing the temperature (Table 7), indicating a more efficient adsorption of BPA and diuron on HTC@ ANS-200 at lower temperatures. The $\Delta \mathrm{H}^{\circ}<0$ suggest the exothermicity of the BPA and diuron adsorption process, which was demonstrated by a decrease in the maximum adsorption capacity $\left(Q_{\max }\right)$. The exothermicity might also 

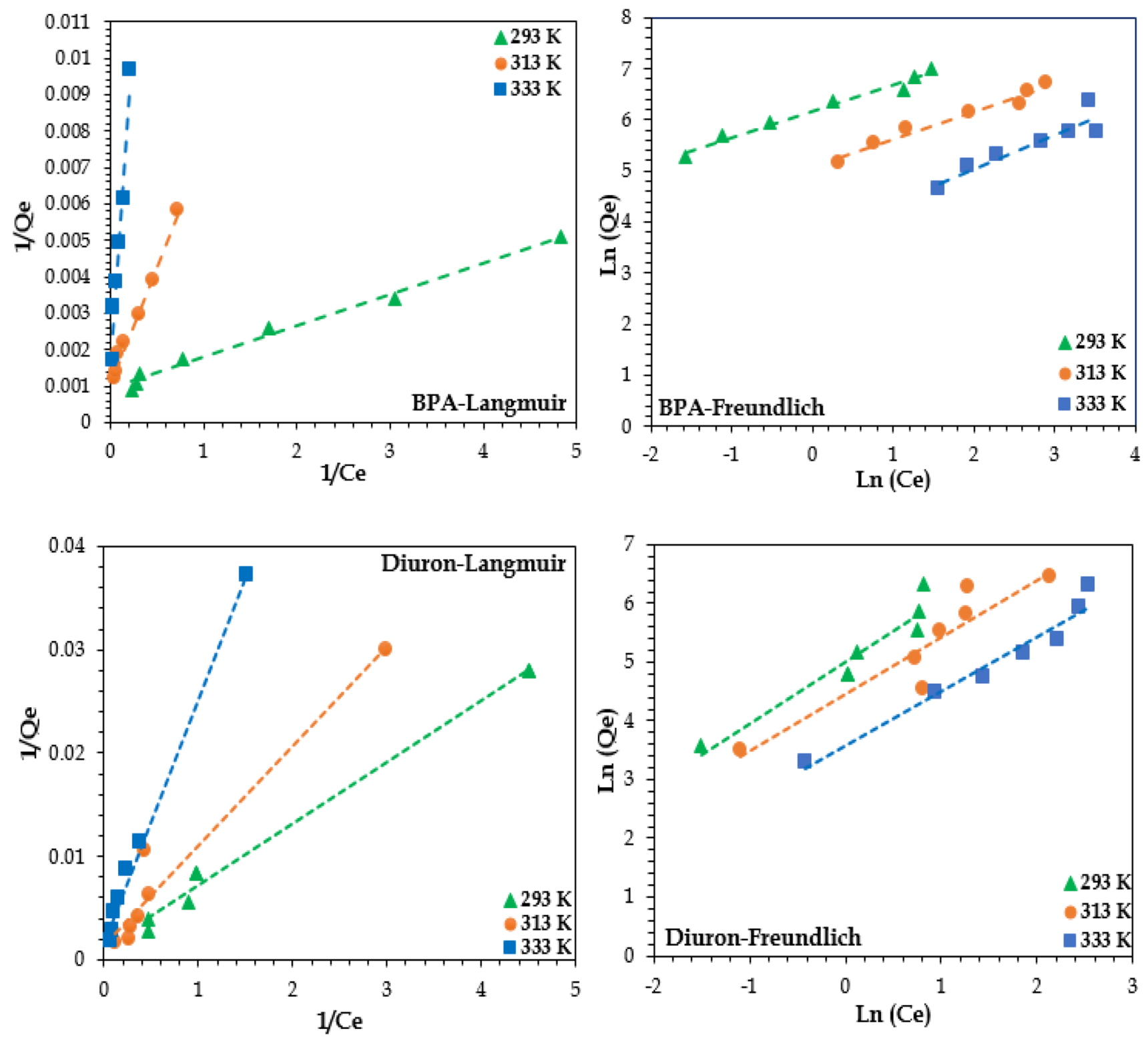

Fig. 13 Langmuir and Freundlich models for BPA and diuron adsorption on HTC@ ANS-200

imply the emission of energy in the form of heat to the surroundings during the adsorption process. The BPA and diuron adsorption phenomenon on HTC@ANS-200 is less random $\left(\Delta S^{\circ}<0\right)$ at the solid-liquid interface during the adsorption process [69].

Thermodynamic investigation plays an essential part in the prediction of BPA and diuron adsorption mechanisms on HTC@ANS-200 (e.g., physical or chemical). However, the adsorption process is based on physisorption, when the $\Delta \mathrm{G}^{\circ}$ values are between 0 and $-20 \mathrm{~kJ} / \mathrm{mol}$, whereas for chemisorption the $\Delta \mathrm{G}^{\circ}$ values are between -80 and $-400 \mathrm{~kJ} /$ mol. In the present study, the $\Delta \mathrm{G}^{\circ}$ values are ranged between -8 and $-13 \mathrm{~kJ} / \mathrm{mol}$ for BPA and between -9 and $-14 \mathrm{~kJ} /$ mol for diuron (Table 7), which means that the adsorption of BPA and diuron on HTC@ANS-200 occurs via physisorption and indicates also the possibility of regeneration of the spent HTC@ANS-200. These results are in good agreement with other studies [61, 70-72].

\section{Adsorption Mechanism}

Functional groups present on the surface of any adsorbent can be considered as an embodiment of structure. Given the FTIR of HTC@ANS-200, BPA, and diuron molecule (Figs. 15,16), the interaction with the functional groups (adsorbate/adsorbent) may be involved in the adsorption 
Table 6 Maximum adsorption capacities of BPA and diuron of different adsorbents

\begin{tabular}{llll}
\hline Adsorbent & $\begin{array}{l}\text { BET surface area } \\
\left(\mathrm{m}^{2} / \mathrm{g}\right)\end{array}$ & $\begin{array}{l}\text { Maximum adsorption } \\
\text { capacity }(\mathrm{mg} / \mathrm{g})\end{array}$ & Reference \\
\hline Bisphenol A & & & Our study \\
HTC@ ANS-200 & 41 & 1162.7 & {$[59]$} \\
AC purchased from Wako & 1350 & 56.5 & {$[60]$} \\
AC purchased from Takeda & 1119 & 23.5 & {$[61]$} \\
Graphene & 327 & 181.6 & {$[45]$} \\
Mesoporous carbon CMK-3 & 920 & 296 & {$[50]$} \\
Activated carbon & 1760 & 432.3 & {$[62]$} \\
Hybrid material (Ph-MS) & 750 & 351 & {$[63]$} \\
Powdered-activated-carbon & - & 771.2 & {$[63]$} \\
CoFe ${ }_{2}$ O $_{4}$ powdered-activated-carbon & - & 727.2 & Our study \\
composite & & & {$[64]$} \\
Diuron & & & {$[64]$} \\
HTC@ ANS-200 & 41 & 333.3 & {$[65]$} \\
Granular activated carbon & 1191 & 316.0 & {$[65]$} \\
Activated carbon fiber & 1709 & 667.2 & {$[66]$} \\
Activated carbon & 776 & 279.4 & {$[67]$} \\
Wheat carbon & 310 & 54.1 & \\
Activated carbon & 1139 & 39.6 & \\
Multiwalled carbon nanotubes & 258.6 & & \\
\hline
\end{tabular}

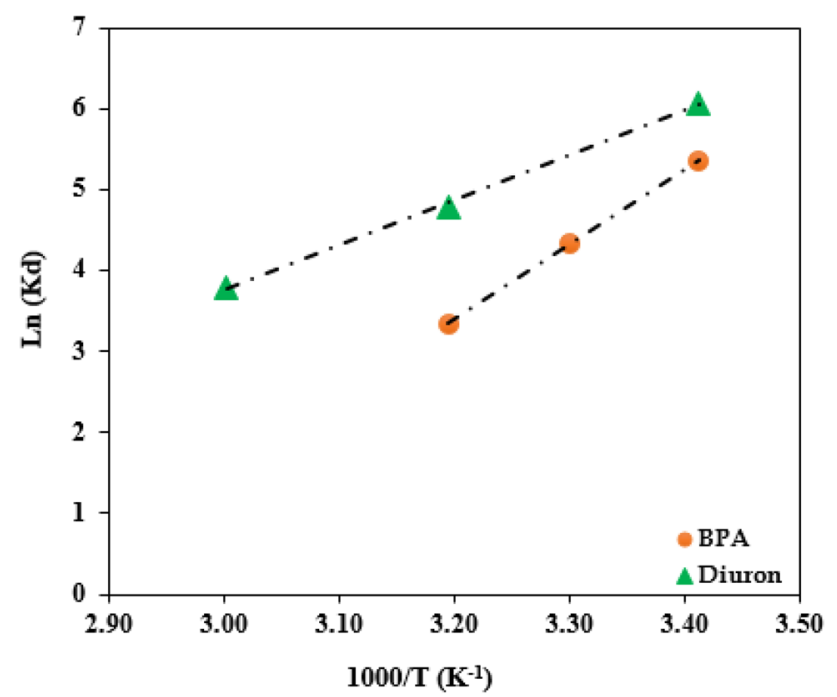

Fig. 14 Plot of $\operatorname{Ln}\left(\mathrm{K}_{\mathrm{d}}\right)$ versus 1/T for thermodynamic parameters calculation for the adsorption of BPA and diuron on HTC@ ANS-200

Table 7 Thermodynamic parameters for the adsorption of BPA and diuron on HTC@ANS-200

\begin{tabular}{lllll}
\hline$\Delta \mathrm{H}(\mathrm{J} / \mathrm{mol})$ & $\Delta \mathrm{S}(\mathrm{kJ} / \mathrm{mol} \mathrm{K})$ & \multicolumn{4}{l}{$\Delta \mathrm{GJ} / \mathrm{mol})$} & \\
\cline { 3 - 5 } & & $293 \mathrm{~K}$ & $313 \mathrm{~K}$ & $333 \mathrm{~K}$ \\
\hline BPA & & -13.024 & -10.925 & -8.705 \\
-76.278 & -0.215 & & & \\
Diuron & & -14.787 & -12.069 & -9.855 \\
-46.360 & -0.107 & & & \\
\hline
\end{tabular}

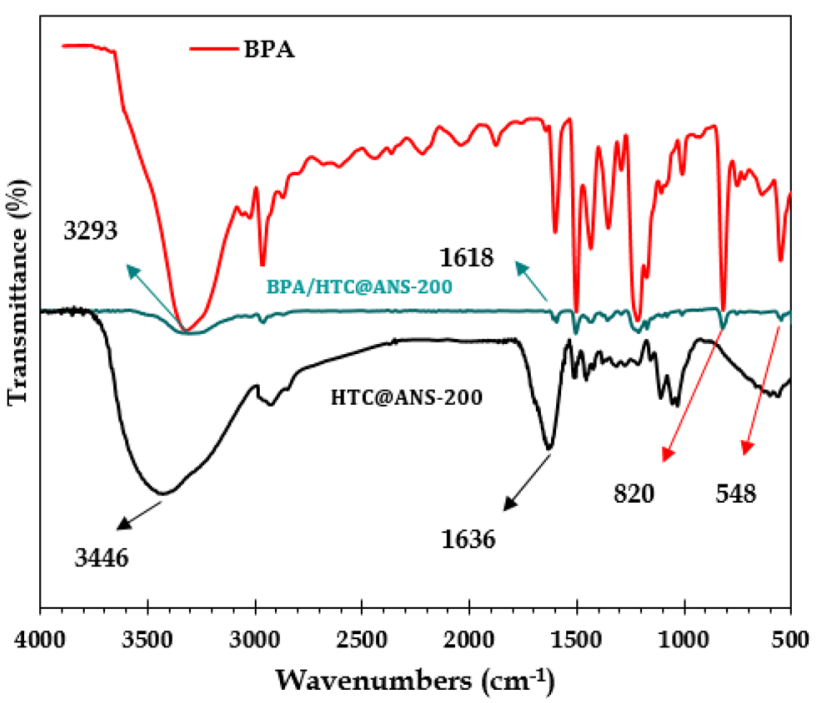

Fig. 15 FTIR spectra of BPA and HTC@ANS-200 after and before the BPA adsorption

process $[73,74]$. It is noted that weak interactions could change the bond lengths or energies and then affect vibration and rotation of molecules. In theory, the $\mathrm{X}-\mathrm{H}$ bond (such as $\mathrm{O}-\mathrm{H}$ and $\mathrm{N}-\mathrm{H}$ ) could lengthen the hydrogen bond, which leads to a shift of the $\mathrm{X}-\mathrm{H}$ stretching frequency. In addition, an increase in the infrared absorption cross-section for the $\mathrm{X}-\mathrm{H}$ stretching of vibrations [75]. The influence of the interaction of the functional groups with BPA and diuron molecules may cause a shift in the infrared peaks [61, 
Fig. 16 FTIR spectra of diuron and HTC@ANS-200 after and before the BPA adsorption
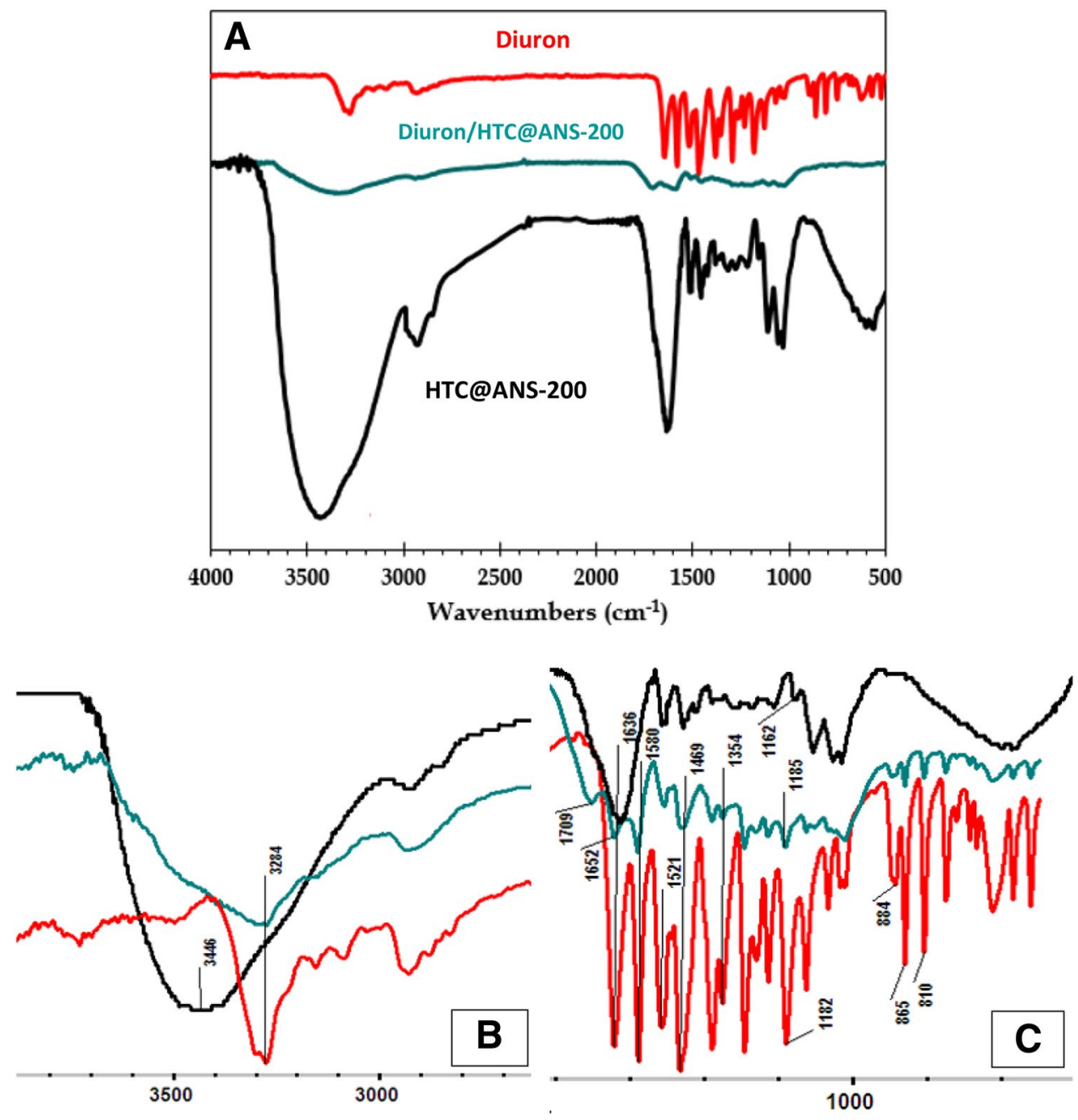

76]. Consequently, a FTIR analysis can be a useful tool for identifying the interactions and to provide information on the functional groups participating in the adsorption of BPA and diuron on HTC@ANS-200. The FTIR spectra of BPA, HTC@ANS-200, and BPA/HTC@ANS-200 are shown in Fig. 15. The wide peak at $3446 \mathrm{~cm}^{-1}$ corresponding to the stretching vibration of O-H groups of HTC@ANS-200 shifted to $3293 \mathrm{~cm}^{-1}$. The shift indicated that the hydroxyl groups take part in the adsorption as hydrogen bonding sites. Also, the $\mathrm{C}=\mathrm{C}$ peak shifted from 1636 to $1618 \mathrm{~cm}^{-1}$ after adsorption, indicating that $\pi-\pi$ interactions also play a role in the adsorption process. These interactions existed between the benzene rings of HTC@ANS-200 and BPA. Two new peaks at $820 \mathrm{~cm}^{-1}$ and $548 \mathrm{~cm}^{-1}$ were observed for the spent HTC@ANS-200, which is in agreement with the peaks from the FTIR spectrum of BPA.

To reveal the adsorption mechanism between HTC@ ANS-200 and diuron. The FTIR spectra of HTC@ANS200, diuron/HTC@ANS-200, and diuron in the frequency range of 4000-500 $\mathrm{cm}^{-1}$ are illustrated in Fig. 16a Several intense characteristic bands in the IR spectra can be related to the functional groups present on HTC@ANS-200 and Diuron/HTC@ANS-200. The strong and broadband between 4000 and $3000 \mathrm{~cm}^{-1}$ could be assigned to $\mathrm{N}-\mathrm{H}$ and $\mathrm{O}-\mathrm{H}$ stretching vibration, which is overlapping after adsorption of diuron on HTC@ANS-200. For diuron, a carbonyl band at $1636 \mathrm{~cm}^{-1}$ and a benzene ring stretching band at 1521,1469 , and $1354 \mathrm{~cm}^{-1}$ were recognized [77, 78]. Other bands located at $1580 \mathrm{~cm}^{-1}$ were assigned to $\mathrm{C}=\mathrm{C}$ stretching vibration, while the band at $1182 \mathrm{~cm}^{-1}$ was due to the $\mathrm{C}-\mathrm{H}$ in-plane bending vibration of the benzene ring. Bands at 810,865 , and $754 \mathrm{~cm}^{-1}$ were assigned mainly to $\mathrm{C}-\mathrm{H}$ outof-plane bending vibration of the benzene ring, and partly $\mathrm{C}-\mathrm{Cl}$ stretching vibration [79]. After adsorption of diuron on HTC@ANS-200, some small bands related to the functional groups of diuron were observed in the FTIR spectra of HTC@ANS-200 (Fig. 16c). For instance, benzene ring bands, specifically at $1469 \mathrm{~cm}^{-1}$, were observed after the adsorption of diuron on HTC@ANS-200. Furthermore, the peak located at $1709 \mathrm{~cm}^{-1}$ was attributed to $\mathrm{C}=\mathrm{O}$ present in the diuron structure. Other peaks appearing between 1000 and $500 \mathrm{~cm}^{-1}$ were assigned to $\mathrm{C}-\mathrm{H}$ out-of-plane bending 
vibration of the benzene ring of diuron [80]. This is because the amount of diuron adsorbed was higher on HTC@ANS200. As can be seen in Fig. 16b the peaks of -OH groups decreased and shifted from 3436 to $3284 \mathrm{~cm}^{-1}$ after the adsorption of diuron. This result suggests that hydrogen bonding can occur between surface hydrogen bonds of the hydroxyl groups on HTC@ ANS-200 and nitrogen atoms present in the diuron structure [81, 82]. In addition, the $\mathrm{C}=\mathrm{C}$ peaks of HTC@ANS-200 decreased and shifted from 1636 to $1652 \mathrm{~cm}^{-1}$, confirming the presence of $\pi-\pi$ interactions occurring between $\pi$-electrons in HTC@ANS-200 and $\pi$-electron in the aromatic ring of diuron [83].

These results are also supported by the analogous chemical structures of HTC@ANS-200, BPA, and diuron. The structure of BPA and diuron consists of hydrophilic groups $(\mathrm{O}-\mathrm{H}$ or $\mathrm{N}-\mathrm{H})$ and hydrophobic benzene rings. This amphiphilic property is similar to HTC@ANS-200, which contains hydrophilic functional groups and hydrophobic basal plane. The compatibility of properties in the adsorbate and adsorbent may lead to strong adsorption [84]. Additionally, the length of BPA and diuron molecules are $0.94 \mathrm{~nm}$ and $0.75 \mathrm{~nm}$, respectively and the average pore size of HTC@
ANS-200 is $2 \mathrm{~nm}$, which shows that BPA and diuron molecules enter easily on the porous structure of HTC@ANS200 and are adsorbed on the adsorption sites. The schematic of the adsorption mechanism of BPA and diuron molecules on HTC@ANS-200 is illustrated in Fig. 17.

\section{Regeneration and Reusability}

To evaluate the possibility of regeneration and reuse of HTC@ ANS-200, ethanol was used to extract the adsorbed BPA and diuron from HTC@ANS-200. The reusability of the HTC@ANS-200 was determined using five adsorption-regeneration cycles. A sample of $0.01 \mathrm{~g}$ of HTC@ ANS-200 was shaken with $200 \mathrm{~mL}$ solution of $60 \mathrm{mg} / \mathrm{L}$ BPA and/or diuron $(40 \mathrm{mg} / \mathrm{L})$ for $2 \mathrm{~h}$ at room temperature. Then, the HTC@ANS-200 was filtered, washed and then dried at $105{ }^{\circ} \mathrm{C}$. After each adsorption, the regeneration process was repeated. Figure 18 shows that the adsorption efficiency of HTC@ ANS-200 after five adsorptionregeneration cycles is $\sim 88 \%$ for BPA and $\sim 94 \%$ for diuron. In addition, the removal rate of bisphenol $\mathrm{A}$ decreased by $4 \%$ after five cycles, while the removal rate of diuron
Fig. 17 Schematic representation of the $\pi-\pi$ interaction and hydrogen-bonding between BPA/HTC@ANS-200 and diuron/HTC@ANS-200

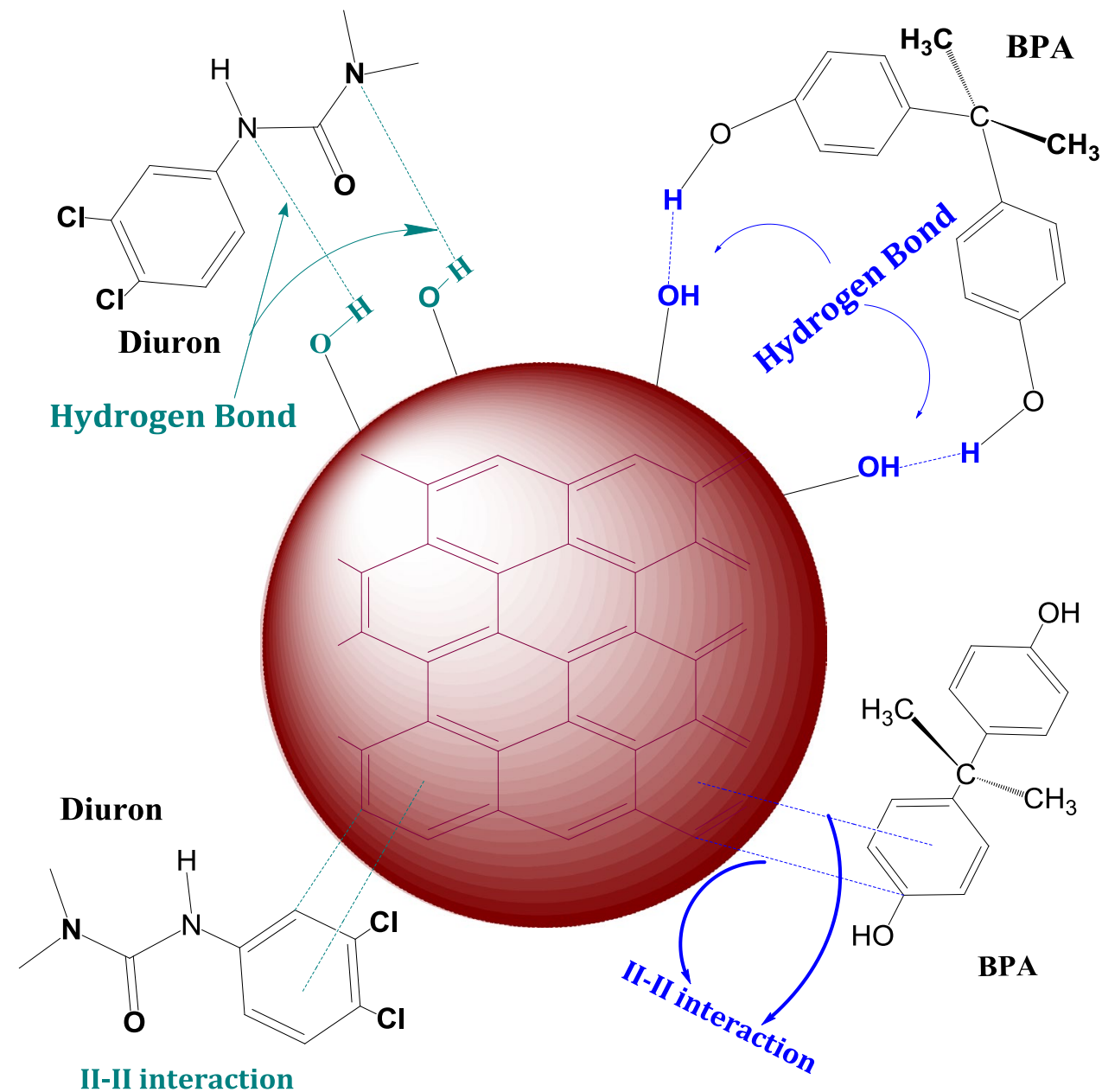




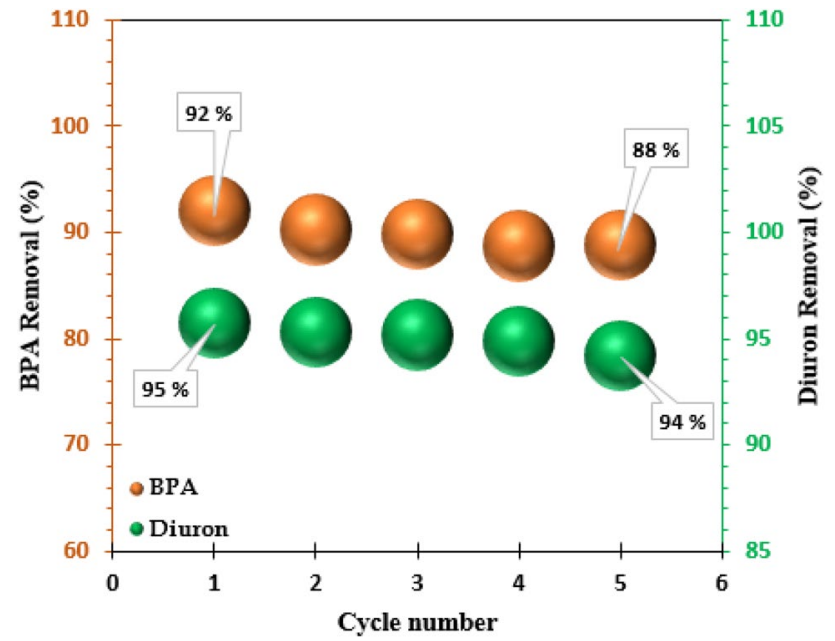

Fig. 18 Reusability of HTC@ANS-200 for the adsorption of $\mathrm{BPA}$ and diuron $\left(\mathrm{C}_{0}=60 \mathrm{mg} / \mathrm{L} ; \mathrm{m}=0.01 \mathrm{~g}\right.$; time $=180$; stirring speed $=200 \mathrm{rpm}$ and temperature $=293 \mathrm{~K}$ )

showed a weak diminution (1\%) after five cycles. This result shows that HTC@ANS-200 exhibits excellent stability and can be used many times without a significant loss in the adsorption efficiency of BPA and diuron. Additional advantage of these economic bio-based compounds is, that at the end of their lifetime, they can be burned in a waste incineration plant, the energy can be recovered, and the harmful compounds retained on the material are incinerated to less harmful oxidation products.

\section{Cost Production}

To estimate the cost production of our material, the Eq. 14 was used. This equation take into consideration the cost of energy consumption and the cost of reagents $[85,86]$.

Operating cost $=\sum C_{\text {energy }}+C_{\text {reagents }}$

where the $\mathrm{C}_{\text {energy }}$ signifies the energy consumption of the materials used in US\$ [87], $\mathrm{C}_{\text {reagents }}$ is the cost of the reagents used in US\$.

The operating costs were calculated as $7.46 \mathrm{US} \$ / \mathrm{Kg}$ of argan nut shell (Table 8). As shown from Table the temperature is the main parameter influence the cost treatment. Generally, carbonaceous materials are prepared at high temperature $\left(>200{ }^{\circ} \mathrm{C}\right)$ under nitrogen atmosphere, which may increase the production cost [88]. Accordingly, the hydrothermal carbonization method allows us to produce low-cost material compared to activated carbon. This
Table 8 Operating cost of production of our material

\begin{tabular}{lll}
\hline Parameters & Approx. consumption & Cost \$ \\
\hline $\begin{array}{l}\text { Hydrothermal carboniza- } \\
\text { tion }\left(200^{\circ} \mathrm{C} / 6 \mathrm{~h}\right)\end{array}$ & $1.7 \mathrm{kWh}^{-1}$ & 1.53 \\
$\mathrm{H}_{2} \mathrm{SO}_{4}(18 \mathrm{~N})$ & $10 \mathrm{~mL}$ & \\
Oven $\left(80^{\circ} \mathrm{C} / 12 \mathrm{~h}\right)$ & $1 \mathrm{kWh}^{-1}$ & 0.56 \\
Argan Nut Shell & $300 \mathrm{~g}$ & $0.15^{\mathrm{a}}$ \\
& & Free $^{\mathrm{b}}$ \\
& & $\mathrm{Sum}=2.24$ \\
& $\mathrm{US} \$ / 300 \mathrm{~g}$ \\
\hline
\end{tabular}

${ }^{\mathrm{a}}$ The rate of electricity $0.15 \mathrm{US} \$$ for $\mathrm{kWh}^{-1}$

${ }^{\mathrm{b}}$ Waste material

cost confirm that our material was recommendable for a possible industrial application.

\section{Conclusion}

Argan nut shell-derived hydrochars (HTC@ANS-180 and HTC@ANS-200) prepared through hydrothermal carbonization process exhibited a mesoporous structure and essential amount of surface functional groups was preserved after the HTC processing. The Langmuir isotherm model described well the BPA and diuron adsorption on HTC@ ANS-200. The increase in temperature from 293 to $333 \mathrm{~K}$ decreased the amount of adsorbed BPA and diuron on HTC@ANS-200. The best adsorption of BPA and diuron on HTC@ANS-200 occurred at $\mathrm{pH}$ value close to the $\mathrm{pH}_{\mathrm{PZC}}$ value (7.3) of HTC@ ANS-200. The adsorption mechanism of BPA and diuron on HTC@ ANS-200 was mainly due to the $\pi-\pi$ interactions and hydrogen bonding. The thermodynamic investigation demonstrated that the adsorption process of BPA and diuron on HTC@ANS-200 was spontaneous $\left(\Delta G^{\circ}<0\right)$ and exothermic $\left(\Delta \mathrm{H}^{\circ}<0\right)$. More importantly, it was demonstrated that HTC@ ANS-200 exhibited fast adsorption with high adsorption capacity $(\mathrm{BPA}=1162.9 \mathrm{mg} / \mathrm{g}$ and diuron $=833.3 \mathrm{mg} / \mathrm{g})$, which were better than those reported earlier in the literature. Furthermore, an excellent reusability (after five cycles, the removal rate of diuron showed a weak diminution of $4 \%$ for BPA and 1\% for diuron) of HTC@ ANS-200 was observed. The outcome of this study does not only open up a novel way to recycle waste biomass (argan nut shell), but also presents a beneficial approach to synthesize functional mesoporous lowcost materials, that are promising adsorbent for wastewater treatment.

Acknowledgements Open access funding provided by University of Oulu including Oulu University Hospital. The research leading to these results has received funding from the European Union Seventh 
Framework Programme (FP/2007-2013) under the Grant Agreement No. [PIRSES-GA-2012-317714] No-Waste.

Open Access This article is distributed under the terms of the Creative Commons Attribution 4.0 International License (http://creativeco mmons.org/licenses/by/4.0/), which permits unrestricted use, distribution, and reproduction in any medium, provided you give appropriate credit to the original author(s) and the source, provide a link to the Creative Commons license, and indicate if changes were made.

\section{References}

1. Berggius, F.: Chemical Reactions Under High Pressure. Nobel Lectures in Chemistry. World Scientific, Singapore, pp 244-276 (1932)

2. Bergius, F.: Beitrage zur theorie der kohleentstehung. Naturwissenschaften. 16, 1-10 (1928). https://doi.org/10.1007/BF015 04496

3. Berl, E., Schmidt, A.: Über das verhalten der cellulose bei der druckerhitzung mit wasser. Justus Liebigs Ann. Chem. 461, 192-220 (1928). https://doi.org/10.1002/jlac.19284610110

4. Berl, E., Schmidt, A., Koch, H.: Über die entstehung der kohlen. Angew. Chemie. 45, 517-519 (1932). https://doi.org/10.1002/ ange. 19320453202

5. Wang, Q., Li, H., Chen, L., Huang, X.: Monodispersed hard carbon spherules with uniform nanopores. Carbon N. Y. 39, 22112214 (2001). https://doi.org/10.1016/S0008-6223(01)00040-9

6. Haenel, M.W.: Recent progress in coal structure research. Fuel. 71, 1211-1223 (1992). https://doi.org/10.1016/00162361(92)90046-Q

7. Lu, X., Jordan, B., Berge, N.D.: Thermal conversion of municipal solid waste via hydrothermal carbonization: comparison of carbonization products to products from current waste management techniques. Waste Manag. 32, 1353-1365 (2012). https:// doi.org/10.1016/j.wasman.2012.02.012

8. Liu, Z., Balasubramanian, R.: Hydrothermal carbonization of waste biomass for nergy generation. Procedia Environ. Sci. 16, 159-166 (2012). https://doi.org/10.1016/j.proenv.2012.10.022

9. Titirici, M.-M., Antonietti, M., Baccile, N.: Hydrothermal carbon from biomass: a comparison of the local structure from poly- to monosaccharides and pentoses/hexoses. Green Chem. 10, 1204-1212 (2008). https://doi.org/10.1039/B807009A

10. Zbair, M., Ainassaari, K., Drif, A., Ojala, S., Bottlinger, M., Pirilä, M., Keiski, R.L., Bensitel, M., Brahmi, R.: Toward new benchmark adsorbents: preparation and characterization of activated carbon from argan nut shell for bisphenol A removal. Environ. Sci. Pollut. Res. 25, 1869-1882 (2018). https://doi. org/10.1007/s11356-017-0634-6

11. Zbair, M., Anfar, Z., Ahsaine, H.A., El Alem, N., Ezahri, M.: Acridine orange adsorption by zinc oxide/almond shell activated carbon composite: operational factors, mechanism and performance optimization using central composite design and surface modeling. J. Environ. Manag. 206, 383-397 (2018). https://doi.org/10.1016/j.jenvman.2017.10.058

12. Anfar, Z., El Haouti, R., Lhanafi, S., Benafqir, M., Azougarh, Y., El Alem, N.: Treated digested residue during anaerobic co-digestion of Agri-food organic waste: methylene blue adsorption, mechanism and CCD-RSM design. J. Environ. Chem. Eng. 5, 5857-5867 (2017). https://doi.org/10.1016/j. jece.2017.11.015

13. Xu, Y.-J., Weinberg, G., Liu, X., Timpe, O., Schlögl, R., Su, D.S.: Nanoarchitecturing of activated carbon: facile strategy for chemical functionalization of the surface of activated carbon. Adv. Funct. Mater. 18, 3613-3619 (2008). https://doi. org/10.1002/adfm.200800726

14. Demir-Cakan, R., Baccile, N., Antonietti, M., Titirici, M.-M.: Carboxylate-rich carbonaceous materials via one-step hydrothermal carbonization of glucose in the presence of acrylic acid. Chem. Mater. 21, 484-490 (2009). https://doi.org/10.1021/cm802141h

15. Mäkelä, M., Benavente, V., Fullana, A.: Hydrothermal carbonization of lignocellulosic biomass: effect of process conditions on hydrochar properties. Appl. Energy. 155, 576-584 (2015). https://doi.org/10.1016/j.apenergy.2015.06.022

16. Li, P., Wang, X., Allinson, G., Li, X., Xiong, X.: Risk assessment of heavy metals in soil previously irrigated with industrial wastewater in Shenyang. China. J. Hazard. Mater. 161, 516-521 (2009). https://doi.org/10.1016/j.jhazmat.2008.03.130

17. Newman, A.: Ranking pesticides by environmental impact. Environ. Sci. Technol. 29, 324A-326A (1995). https://doi. org/10.1021/es00007a003

18. Kolpin, D.W., Furlong, E.T., Meyer, M.T., Thurman, E.M., Zaugg, S.D., Barber, L.B., Buxton, H.T.: Pharmaceuticals, hormones, and other organic wastewater contaminants in U.S. streams, 1999-2000: a national reconnaissance. Environ. Sci. Technol. 36, 1202-1211 (2002). https://doi.org/10.1021/es011 $055 \mathrm{j}$

19. Yamamoto, T., Yasuhara, A., Shiraishi, H., Nakasugi, O.: Bisphenol A in hazardous waste landfill leachates. Chemosphere. 42, 415-418 (2001). https://doi.org/10.1016/S0045-6535(00)00079-5

20. Wetherill, Y.B., Akingbemi, B.T., Kanno, J., McLachlan, J.A., Nadal, A., Sonnenschein, C., Watson, C.S., Zoeller, R.T., Belcher, S.M.: In vitro molecular mechanisms of bisphenol A action. Reprod. Toxicol. 24, 178-198 (2007). https://doi.org/10.1016/j. reprotox.2007.05.010

21. Chen, W., Yu, H., Liu, Y., Chen, P., Zhang, M., Hai, Y.: Individualization of cellulose nanofibers from wood using high-intensity ultrasonication combined with chemical pretreatments. Carbohydr. Polym. 83, 1804-1811 (2011). https://doi.org/10.1016/j. carbpol.2010.10.040

22. Anfar, Z., Zbair, M., Ahsaine, H.A., Ezahri, M., Alem, N.E.: Well-designed $\mathrm{WO}_{3}$ /activated carbon composite for Rhodamin. Removal: synthesis, characterization, and modeling using response surface methodology. Fuller. Nanotub. Carbon Nanostruct. 26, 389-397 (2018). https://doi.org/10.1080/15363 83X.2018.1440386

23. Ahsaine, H.A., Zbair, M., Anfar, Z., Naciri, Y., El Alem, N., Ezahri, M.: Cationic dyes adsorption onto high surface area 'almond shell' activated carbon: kinetics, equilibrium isotherms and surface statistical modeling. Mater. Today Chem. 8, 121-132 (2018). https://doi.org/10.1016/j.mtchem.2018.03.004

24. Yang, T., Lua, A.C.: Textural and chemical properties of zinc chloride activated carbons prepared from pistachio-nut shells. Mater Chem. Phys. 100, 438-444 (2006). https://doi.org/10.1016/j.match emphys.2006.01.039

25. Marx, S., Chiyanzu, I., Piyo, N.: Influence of reaction atmosphere and solvent on biochar yield and characteristics. Bioresour. Technol. 164, 177-183 (2014). https://doi.org/10.1016/j.biort ech.2014.04.067

26. Xu, Q., Qian, Q., Quek, A., Ai, N., Zeng, G., Wang, J.: Hydrothermal carbonization of macroalgae and the effects of experimental parameters on the properties of hydrochars. ACS Sustain. Chem. Eng. 1, 1092-1101 (2013). https://doi.org/10.1021/sc400118f

27. Volpe, M., Fiori, L.: From olive waste to solid biofuel through hydrothermal carbonisation: the role of temperature and solid load on secondary char formation and hydrochar energy properties. J. Anal. Appl. Pyrolysis. 124, 63-72 (2017). https://doi. org/10.1016/j.jaap.2017.02.022 
28. Reza, M.T., Lynam, J., Uddin, M.H., Coronella, C.: Hydrothermal carbonization: fate of inorganics. Biomass Bioenergy. 49, 86-94 (2013). https://doi.org/10.1016/j.biombioe.2012.12.004

29. Codignole Luz, F., Volpe, M., Fiori, L., Manni, A., Cordiner, S., Mulone, V., Rocco, V.: Spent coffee enhanced biomethane potential via an integrated hydrothermal carbonization-anaerobic digestion process. Bioresour. Technol. 256, 102-109 (2018). https ://doi.org/10.1016/j.biortech.2018.02.021

30. Hoekman, S.K., Broch, A., Robbins, C.: Hydrothermal carbonization (HTC) of lignocellulosic biomass. Energy Fuels. 25, 18021810 (2011). https://doi.org/10.1021/ef101745n

31. Xiu, S., Shahbazi, A., Shirley, V., Cheng, D.: Hydrothermal pyrolysis of swine manure to bio-oil: effects of operating parameters on products yield and characterization of bio-oil. J. Anal. Appl. Pyrolysis. 88, 73-79 (2010). https://doi.org/10.1016/j. jaap.2010.02.011

32. Xiao, L.-P., Shi, Z.-J., Xu, F., Sun, R.-C.: Hydrothermal carbonization of lignocellulosic biomass. Bioresour. Technol. 118, 619-623 (2012). https://doi.org/10.1016/j.biortech.2012.05.060

33. Kumar, A., Negi, Y.S., Bhardwaj, N.K., Choudhary, V.: Synthesis and characterization of methylcellulose/PVA based porous composite. Carbohydr. Polym. 88, 1364-1372 (2012). https://doi. org/10.1016/j.carbpol.2012.02.019

34. Wada, M., Heux, L., Sugiyama, J.: Polymorphism of cellulose I family: reinvestigation of cellulose IVI. Biomacromolecules. 5, 1385-1391 (2004). https://doi.org/10.1021/bm0345357

35. Kumar, A., Negi, Y.S., Choudhary, V., Bhardwaj, N.K.: Characterization of cellulose nanocrystals produced by acid-hydrolysis from sugarcane bagasse as agro-waste. J. Mater. Phys. Chem. 2, 1-8 (2014). https://doi.org/10.12691/jmpc-2-1-1

36. El-Nabarawy, T., Petro, N.S., Abdel-Aziz, S.: Adsorption characteristics of coal-based activated carbons. II. Adsorption of water vapour, pyridine and benzene. Adsorpt. Sci. Technol. 15, 47-57 (1997). https://doi.org/10.1177/026361749701500105

37. Figueiredo, J., Pereira, M.F., Freitas, M.M., Órfão, J.J.: Modification of the surface chemistry of activated carbons. Carbon N. Y. 37, 1379-1389 (1999). https://doi.org/10.1016/S0008 $-6223(98) 00333-9$

38. Bouchelta, C., Medjram, M.S., Bertrand, O., Bellat, J.-P.: Preparation and characterization of activated carbon from date stones by physical activation with steam. J. Anal. Appl. Pyrolysis. 82, 70-77 (2008). https://doi.org/10.1016/j.jaap.2007.12.009

39. Fonts, I., Azuara, M., Gea, G., Murillo, M.B.: Study of the pyrolysis liquids obtained from different sewage sludge. J. Anal. Appl. Pyrolysis. 85, 184-191 (2009). https://doi.org/10.1016/j. jaap.2008.11.003

40. Ji, Y., Li, T., Zhu, L., Wang, X., Lin, Q.: Preparation of activated carbons by microwave heating $\{\mathrm{KOH}\}$ activation. Appl. Surf. Sci. 254, 506-512 (2007). https://doi.org/10.1016/j.apsus c. 2007.06.034

41. Sevilla, M., Maciá-Agulló, J.A., Fuertes, A.B.: Hydrothermal carbonization of biomass as a route for the sequestration of $\mathrm{CO}_{2}$ : chemical and structural properties of the carbonized products. Biomass Bioenergy. 35, 3152-3159 (2011). https://doi. org/10.1016/j.biombioe.2011.04.032

42. Sevilla, M.: Fuertes, A.: Chemical and structural properties of carbonaceous products obtained by hydrothermal carbonization of saccharides. Chem. Eur. J. 15, 4195-4203 (2009). https://doi. org/10.1002/chem.200802097

43. Tran, H.N., You, S.J., Nguyen, T.V., Chao, H.P.: Insight into the adsorption mechanism of cationic dye onto biosorbents derived from agricultural wastes. Chem. Eng. Commun. 204, 1020-1036 (2017). https://doi.org/10.1080/00986445.2017.1336090

44. Bautista-Toledo, I., Ferro-García, M.A., Rivera-Utrilla, J., Moreno-Castilla, C., Vegas Fernández, F.J.: Bisphenol A removal from water by activated carbon. Effects of carbon characteristics and solution chemistry. Environ. Sci. Technol. 39, 6246-6250 (2005). https://doi.org/10.1021/es0481169

45. Sui, Q., Huang, J., Liu, Y., Chang, X., Ji, G., Deng, S., Xie, T., Yu, G.: Rapid removal of bisphenol A on highly ordered mesoporous carbon. J. Environ. Sci. 23, 177-182 (2011). https:// doi.org/10.1016/S1001-0742(10)60391-9

46. Tsai, W.-T., Lai, C.-W., Su, T.-Y.: Adsorption of bisphenol-A from aqueous solution onto minerals and carbon adsorbents. J. Hazard. Mater. 134, 169-175 (2006). https://doi.org/10.1016/j.jhazm at.2005.10.055

47. Zbair, M., Ainassaari, K., El Assal, Z., Ojala, S., El Ouahedy, N., Keiski, R.L., Bensitel, M., Brahmi, R.: Steam activation of waste biomass: highly microporous carbon, optimization of bisphenol A, and diuron adsorption by response surface methodology. Environ. Sci. Pollut. Res. (2018). https://doi.org/10.1007/s1135 6-018-3455-3

48. Fontecha-Cámara, M.A., López-Ramón, M.V., Álvarez-Merino, M.A., Moreno-Castilla, C.: Effect of surface chemistry, solution $\mathrm{pH}$, and ionic strength on the removal of herbicides diuron and amitrole from water by an activated carbon fiber. Langmuir. 23, 1242-1247 (2007). https://doi.org/10.1021/la062200f

49. Phatthanakittiphong, T., Seo, G.: Characteristic evaluation of graphene oxide for bisphenol A adsorption in aqueous solution. Nanomaterials 6, 128 (2016). https://doi.org/10.3390/nano607012 8

50. Liu, G., Ma, J., Li, X., Qin, Q.: Adsorption of bisphenol A from aqueous solution onto activated carbons with different modification treatments. J. Hazard. Mater. 164, 1275-1280 (2009). https ://doi.org/10.1016/j.jhazmat.2008.09.038

51. Weber, W.J., Morris, J.C.: Kinetics of adsorption carbon from solutions. J. Sanit. Engeering Div. Proc. Am. Soc. Civ. Eng. 89, 31-60 (1963)

52. Qin, Q., Ma, J., Liu, K.: Adsorption of anionic dyes on ammonium-functionalized MCM-41. J. Hazard. Mater. 162, 133-139 (2009). https://doi.org/10.1016/j.jhazmat.2008.05.016

53. Liu, Y., Luo, C., Sun, J., Li, H., Sun, Z., Yan, S.: Enhanced adsorption removal of methyl orange from aqueous solution by nanostructured proton-containing $\delta-\mathrm{MnO}_{2}$. J. Mater. Chem. A. 3, 5674-5682 (2015). https://doi.org/10.1039/C4TA07112C

54. Suresh, S., Srivastava, V.C., Mishra, I.M.: Adsorption of hydroquinone in aqueous solution by granulated activated carbon. J. Environ. Eng. 137, 1145-1157 (2011). https://doi.org/10.1061/ (ASCE)EE.1943-7870.0000443

55. AL-Othman, Z.A., Ali, R., Naushad, M.: Hexavalent chromium removal from aqueous medium by activated carbon prepared from peanut shell: adsorption kinetics, equilibrium and thermodynamic studies. Chem. Eng. J. 184, 238-247 (2012). https://doi. org/10.1016/j.cej.2012.01.048

56. Langmuir, I.: The adsorption of gases on plane surfaces of glass, mica and platinum. J. Am. Chem. Soc. 40, 1361 (1918)

57. Freundlich, H.M.F.: Over the adsorption in solution. J. Phys. Chem. 57, 385-471 (1906)

58. Fischer, S., Papageorgiou, A.C., Lloyd, J.A., Oh, S.C., Diller, K., Allegretti, F., Klappenberger, F., Seitsonen, A.P., Reichert, J., Barth, J.V.: Self-assembly and chemical modifications of bisphenol $\mathrm{A}$ on $\mathrm{Cu}(111)$ : interplay between ordering and thermally activated stepwise deprotonation. ACS Nano. 8, 207-215 (2014). https://doi.org/10.1021/nn4030493

59. Asada, T., Oikawa, K., Kawata, K., Ishihara, S., Iyobe, T., Yamada, A.: Study of removal effect of bisphenol A and beta-estradiol by porous carbon. J. Health Sci. 50, 588-593 (2004). https://doi. org/10.1248/jhs. 50.588

60. Nakanishi, A., Tamai, M., Kawasaki, N., Nakamura, T., Tanada, S.: Adsorption characteristics of bisphenol A onto carbonaceous materials produced from wood chips as organic waste. J. Colloid Interface Sci. 252, 393-396 (2002) 
61. Xu, J., Wang, L., Zhu, Y.: Decontamination of bisphenol A from aqueous solution by graphene adsorption. Langmuir. 28, 84188425 (2012). https://doi.org/10.1021/la301476p

62. Kim, Y.-H., Lee, B., Choo, K.-H., Choi, S.-J.: Selective adsorption of bisphenol A by organic-inorganic hybrid mesoporous silicas. Microporous Mesoporous Mater. 138, 184-190 (2011). https:// doi.org/10.1016/j.micromeso.2010.09.007

63. Li, Z., Gondal, M.A., Yamani, Z.H.: Preparation of magnetic separable $\mathrm{CoFe} 2 \mathrm{O} 4 / \mathrm{PAC}$ composite and the adsorption of bisphenol A from aqueous solution. J. Saudi Chem. Soc. 18, 208-213 (2014). https://doi.org/10.1016/j.jscs.2011.06.012

64. López-Ramón, M.V., Fontecha-Cámara, M.A., Álvarez-Merino, M.A., Moreno-Castilla, C.: Removal of diuron and amitrole from water under static and dynamic conditions using activated carbons in form of fibers, cloth, and grains. Water Res. 41, 2865-2870 (2007). https://doi.org/10.1016/j.watres.2007.02.059

65. Ángeles Fontecha-Cámara, M., López-Ramón, M.V., ÁlvarezMerino, M.A., Moreno-Castilla, C.: Temperature dependence of herbicide adsorption from aqueous solutions on activated carbon fiber and cloth. Langmuir. 22, 9586-9590 (2006). https://doi. org/10.1021/la061666v

66. Al Bahri, M., Calvo, L., Lemus, J., Gilarranz, M.A., Palomar, J., Rodriguez, J.J.: Mechanistic understanding of the behavior of diuron in the adsorption from water onto activated carbon. Chem. Eng. J. 198, 346-354 (2012). https://doi.org/10.1016/j. cej.2012.06.011

67. Sun, K., Zhang, Z., Gao, B., Wang, Z., Xu, D., Jin, J., Liu, X.: Adsorption of diuron, fluridone and norflurazon on single-walled and multi-walled carbon nanotubes. Sci. Total Environ. 439, 1-7 (2012). https://doi.org/10.1016/j.scitotenv.2012.08.022

68. Ouyang, K., Zhu, C., Zhao, Y., Wang, L., Xie, S., Wang, Q.: Adsorption mechanism of magnetically separable $\mathrm{Fe}_{3} \mathrm{O}_{4}$ /graphene oxide hybrids. Appl. Surf. Sci. 355, 562-569 (2015). https://doi. org/10.1016/j.apsusc.2015.07.109

69. Badruddoza, A.Z.M., Tay, A.S.H., Tan, P.Y., Hidajat, K., Uddin, M.S.: Carboxymethyl- $\beta$-cyclodextrin conjugated magnetic nanoparticles as nano-adsorbents for removal of copper ions: synthesis and adsorption studies. J. Hazard. Mater. 185, 1177-1186 (2011). https://doi.org/10.1016/j.jhazmat.2010.10.029

70. Hosseini-Bandegharaei, A., Hosseini, M.S., Sarw-Ghadi, M., Zowghi, S., Hosseini, E., Hosseini-Bandegharaei, H.: Kinetics, equilibrium and thermodynamic study of $\mathrm{Cr}(\mathrm{VI})$ sorption into toluidine blue o-impregnated XAD-7 resin beads and its application for the treatment of wastewaters containing $\mathrm{Cr}(\mathrm{VI})$. Chem. Eng. J. 160, 190-198 (2010). https://doi.org/10.1016/j. cej.2010.03.040

71. Kwon, J., Lee, B.: Bisphenol A adsorption using reduced graphene oxide prepared by physical and chemical reduction methods. Chem. Eng. Res. Des. 104, 519-529 (2015). https://doi. org/10.1016/j.cherd.2015.09.007

72. Deokar, S.K., Singh, D., Modak, S., Mandavgane, S.A., Kulkarni, B.D.: Adsorptive removal of diuron on biomass ashes: a comparative study using rice husk ash and bagasse fly ash as adsorbents. Desalin. Water Treat. 57, 22378-22391 (2016). https://doi. org/10.1080/19443994.2015.1132394

73. Ahsaine, H.A., Zbair, M., El Haouti, R.: Mesoporous treated sewage sludge as outstanding low-cost adsorbent for cadmium removal. Desalin. Water Treat. 85, 330-338 (2017). https://doi. org/10.5004/dwt.2017.21310

74. Elouahli, A., Zbair, M., Anfar, Z., Ahsaine, H.A., Khallok, H., Chourak, R., Hatim, Z.: Apatitic tricalcium phosphate powder: high sorption capacity of hexavalent chromium removal. Surf. Interfaces. 13, 139-147 (2018). https://doi.org/10.1016/j.surfi n.2018.09.006

75. Arunan, E., Desiraju, G.R., Klein R.A., Sadlej, J., Scheiner, S., Alkorta, I., Clary, D.C., Crabtree, R.H., Dannenberg, J.J., Hobza,
P., Kjaergaad, H.G., Legon, A.C., Mennucci, B., Nesbitt, D.J.: Definition of the hydrogen bond (IUPAC Recommendations 2011). (2011). https://www.degruyter.com/view/j/pac.2011.83. issue-8/pac-rec-10-01-02/pac-rec-10-01-02.xml

76. Salim, C.J., Liu, H., Kennedy, J.F.: Comparative study of the adsorption on chitosan beads of phthalate esters and their degradation products. Carbohydr. Polym. 81, 640-644 (2010). https:// doi.org/10.1016/j.carbpol.2010.03.024

77. Armenta, S., Quintaa, G., Morales, A., Garrigues, S., de la Guardia, M.: FTIR approaches for diuron determination in commercial pesticide formulations. J. Agric. Food Chem. 53, 5842-5847 (2005). https://doi.org/10.1021/jf050268f

78. Lin-Vien, D., Colthup, N., Fateley, W., Grasselli, J.: Compounds containing the carbonyl group. In: Lin-Vien, D., Colthup, N., Fateley, W., Grasselli, J. (eds.) The Handbook of IR and Raman Characteristic Frequencies of Organic Molecules. pp. 117-154. Springer, New York (1900)

79. Chen, G., Academy, C., Academy, Z.P.C., Wang, H., Academy, C.: Adsorption of diuron and dichlobenil on multiwalled carbon nanotubes as affected by lead. J. Hazard. Mater. 188, 156-163 (2011). https://doi.org/10.1016/j.jhazmat.2011.01.095

80. Ghafar, H.H.A., Aty, A.M.A., Gad-allah, T.A., Ali, M.E.M., Abdel-ghafar, H.H.: Parametric, equilibrium, and kinetic studies on biosorption of diuron by anabaena sphaerica and scenedesmus obliquus parametric, equilibrium, and kinetic studies on biosorption of diuron by anabaena sphaerica and scenedesmus obliquus. Environ. Prog. Sustain. Energy. 34, 504-511 (2014). https://doi. org/10.1002/ep.12027

81. Coughlin, R.W., Ezra, F.S.: Role of surface acidity in the adsorption of organic pollutants on the surface of carbon. Environ. Sci. Technol. 2, 291-297 (1968). https://doi.org/10.1021/es60016a00 2

82. Tran, H.N., You, S.-J., Chao, H.-P.: Fast and efficient adsorption of methylene green 5 on activated carbon prepared from new chemical activation method. J. Environ. Manage. 188, 322-336 (2017). https://doi.org/10.1016/j.jenvman.2016.12.003

83. Tran, H.N., You, S.-J., Chao, H.-P.: Insight into adsorption mechanism of cationic dye onto agricultural residues-derived hydrochars: negligible role of $\pi-\pi$ interaction. Korean J. Chem. Eng. 34, 1708-1720 (2017). https://doi.org/10.1007/s11814-017-0056-7

84. Phatthanakittiphong, T., Seo, G.T.: Characteristic evaluation of graphene oxide for bisphenol A adsorption in aqueous solution. Nanomaterials. 6, 128 (2016). https://doi.org/10.3390/nano6070128

85. Dalvand, A., Gholami, M., Joneidi, A., Mahmoodi, N.M.: Dye removal, energy consumption and operating cost of electrocoagulation of textile wastewater as a clean process. Clean-Soil, Air, Water. 39, 665-672 (2011)

86. Saad, M., Tahir, H., Ali, D.: Green Synthesis of Ag-Cr-AC Nanocomposites by Azadirachta indica and its application for the Simultaneous Removal of binary mixture of dyes by ultrasonicated assisted adsorption process using Response Surface Methodology Department of Chemistry, Universi. Ultrason. Sonochem. (2017). https://doi.org/10.1016/j.ultsonch.2017.03.022

87. Bello, O.S.: Adsorptive removal of malachite green with activated carbon prepared from oil palm fruit fibre by $\mathrm{KOH}$ activation and $\mathrm{CO}_{2}$ gasification. S. Afr. J. Chem. 66, 00-00 (2013)

88. Zbair, M., Ahsaine, H.A., Anfar, Z.: Porous carbon by microwave assisted pyrolysis: an effective and low-cost adsorbent for sulfamethoxazole adsorption and optimization using response surface methodology. J. Clean. Prod. 202, 571-581 (2018). https://doi. org/10.1016/j.jclepro.2018.08.155

Publisher's Note Springer Nature remains neutral with regard to jurisdictional claims in published maps and institutional affiliations. 